\title{
Advances and Prospects of Phenolic Acids Production, Biorefinery and Analysis
}

\author{
Egle Valanciene $\mathbb{}^{\circledR}$, Ilona Jonuskiene, Michail Syrpas $₫$, Ernesta Augustiniene ${ }^{\circledR}$, \\ Paulius Matulis $\mathbb{D}$, Andrius Simonavicius and Naglis Malys *(D) \\ Bioprocess Research Centre, Faculty of Chemical Technology, Kaunas University of Technology, Radvilènu pl. \\ 19, Kaunas LT-50254, Lithuania; egle.valanciene@ktu.lt (E.V.); ilona.jonuskiene@ktu.lt (I.J.); \\ michail.syrpas@ktu.lt (M.S.); ernesta.augustiniene@ktu.lt (E.A.); paulius.matulis@ktu.lt (P.M.); \\ andrius.simonavicius@ktu.lt (A.S.) \\ * Correspondence: naglis.malys@ktu.lt
}

Received: 30 April 2020; Accepted: 3 June 2020; Published: 6 June 2020

\begin{abstract}
Biotechnological production of phenolic acids is attracting increased interest due to their superior antioxidant activity, as well as other antimicrobial, dietary, and health benefits. As secondary metabolites, primarily found in plants and fungi, they are effective free radical scavengers due to the phenolic group available in their structure. Therefore, phenolic acids are widely utilised by pharmaceutical, food, cosmetic, and chemical industries. A demand for phenolic acids is mostly satisfied by utilising chemically synthesised compounds, with only a low quantity obtained from natural sources. As an alternative to chemical synthesis, environmentally friendly bio-based technologies are necessary for development in large-scale production. One of the most promising sustainable technologies is the utilisation of microbial cell factories for biosynthesis of phenolic acids. In this paper, we perform a systematic comparison of the best known natural sources of phenolic acids. The advances and prospects in the development of microbial cell factories for biosynthesis of these bioactive compounds are discussed in more detail. A special consideration is given to the modern production methods and analytics of phenolic acids.
\end{abstract}

Keywords: phenolic acid; antioxidant activity; biorefinery; extraction; analytical methods; metabolic engineering; microbial fermentation; biosensor

\section{Introduction}

Phenolic acids, alongside simple phenols, hydrolysable tannins, acetophenones, lignans, coumarins, benzophenones, xanthones, stilbenes, and secoiridoids, belong to a large group of aromatic compounds, often referred to as phenolic compounds or phenolics [1-3]. Phenolics are secondary metabolites that are naturally biosynthesised by plants and fungi. They contribute to diverse biological functions ranging from signalling and structural to defensive against biotic (infection, limitation, or excess of nutrients) and abiotic (extreme temperature, UV, and visible light) factors [4-6]. Phenolics have been proven to offer multiple health benefits to humans and animals. For their antioxidative, anticarcinogenic, anti-inflammatory, and antibacterial activities involving free radical scavenging, metal chelation, reducing capacity, and contribution to the modulation of signal transduction and enzymatic activity, phenolics are implicated in reducing the risk of cancer, as well as infectious and cardiovascular diseases [7,8]. Moreover, phenolics provide different qualities to food and beverages including colour, flavour, bitterness, odour, and preservative characteristics [9].

Phenolic acids form one of the largest groups of phenolic compounds and are distinguishable from other phenolics by their structure, which typically contains a carboxyl group and one or more hydroxyl groups bonded to the aromatic ring [10]. The hydroxyl groups and other functional groups attached 
to the aromatic ring determine the bioactive properties of phenolic acids [11]. Similarly to other phenolic compounds, the phenolic acids exhibit antioxidant, antimicrobial, antiviral, antimutagenic, or anticancer activity [12-17]. They reduce oxidative damage or stress in the cells, reducing the risk of diseases. Phenolic acids such as syringic (11), gentisic (12), and gallic (8) acids show activity in chronic live injuries, diabetes, memory loss, and wound healing [18-22]. Anti-aging, anti-wrinkle, and skin whitening effects have been for ferulic and gallic acids $[23,24]$. Other promising therapeutic applications of phenolic acids have recently been reviewed in [1].

Importantly, phenolic acids are industrially relevant compounds, finding use and application in the food, pharmaceutical, cosmetic, and chemical industries. For example, it is expected that the salicylic acid (2) market size will grow exponentially by 2025, driven by increasing consumer inclination towards the health benefits of salicylic acid-concentrated cosmetic products. In 2018, the revenue generated from the cosmetic ingredient market globally was valued at over USD 500 billion [25]. The natural ferulic acid market size was over USD 35 million in 2018, and the industry expects consumption at over 750 tons by 2025 [26]. Ferulic acid is now widely used in the food and cosmetics industries. It is used as the raw material for the production of vanillin and preservatives, as a cross-linking agent for the preparation of food gels and edible films, and as an ingredient in skin protection agents [27]. Gallic acid has a diverse range of industrial uses, such as in the pharmaceutical, cosmetic, food and feed, ink and dye, and paper industries, among others [28].

Vanillic acid (4) is utilised as a pharmaceutical intermediate and as an important component of flavour and fragrances [29]. Nowadays, many compounds, including phenolic acids, can be produced using engineered microorganisms. These microbial cell factories can be cost-effective and environmentally friendly alternatives, delivering the yield and purity of compounds that are higher than those extracted from plants [30,31]. Notably, phenolic acids produced in plants are usually found in conjugated form, often covalently bound to carbohydrates [32], whereas the same phenolic acids produced by microorganisms are obtained as free compounds. The conjugated or free forms of these compounds are bioavailable and may be assimilated by humans $[32,33]$.

This paper focuses firstly on natural sources and properties of phenolic acids. It introduces into methodologies used for the extraction of these bioactive compounds. The strategies for production of phenolic acids using conventional plant sources and metabolically engineered microorganisms are comparatively assessed. Metabolic engineering advances for biosynthesis of ferulic, gallic, salicylic (2), and p-coumaric (26) acids are exemplified. The development and use of new tools, such as clustered regularly interspaced short palindromic repeats associated protein 9 (CRISPR-Cas9) system and genetically encoded biosensors, to improve phenolic acid production is emphasised.

\section{Chemical Structure and Overview of Phenolic Acids}

Phenolic acids are typically divided into hydroxybenzoic and hydroxycinnamic acids. The phenolic acids and their structural characteristics are presented in Tables 1 and 2. In addition, all hydroxycinnamic acids in plants and produced by microorganisms are usually found as trans-geometric isomers. 
Table 1. The structure of hydroxybenzoic acids. The table represents the functional groups of aromatic ring.<smiles>[R6]c1c([R])c([R])c(C(=O)O)c([R])c1[R]</smiles>

\begin{tabular}{|c|c|c|c|c|c|c|}
\hline Number & Hydroxybenzoic Acid & $\mathbf{R}_{\mathbf{1}}$ & $\mathbf{R}_{\mathbf{2}}$ & $\mathbf{R}_{3}$ & $\mathbf{R}_{4}$ & $\mathbf{R}_{5}$ \\
\hline 1 & $p$-Hydroxybenzoic acid & & & $\mathrm{OH}$ & & \\
\hline 2 & Salicylic acid & $\mathrm{OH}$ & & & & \\
\hline 3 & $m$-Hydroxybenzoic acid & & $\mathrm{OH}$ & & & \\
\hline 4 & Vanillic acid & & $\mathrm{CH}_{3} \mathrm{O}$ & $\mathrm{OH}$ & & \\
\hline 5 & Isovanillic acid & & $\mathrm{OH}$ & $\mathrm{CH}_{3} \mathrm{O}$ & & \\
\hline 6 & 5-Hydroxyisovanillic acid & & $\mathrm{OH}$ & $\mathrm{CH}_{3} \mathrm{O}$ & $\mathrm{OH}$ & \\
\hline 7 & $o$-Vanillic acid & $\mathrm{OH}$ & $\mathrm{CH}_{3} \mathrm{O}$ & & & \\
\hline 8 & Gallic acid & & $\mathrm{OH}$ & $\mathrm{OH}$ & $\mathrm{OH}$ & \\
\hline 9 & Hypogallic acid & $\mathrm{OH}$ & $\mathrm{OH}$ & & & \\
\hline 10 & Protocatechuic acid & & $\mathrm{OH}$ & $\mathrm{OH}$ & & \\
\hline 11 & Syringic acid & & $\mathrm{CH}_{3} \mathrm{O}$ & $\mathrm{OH}$ & $\mathrm{CH}_{3} \mathrm{O}$ & \\
\hline 12 & Gentisic acid & $\mathrm{OH}$ & & & $\mathrm{OH}$ & \\
\hline 13 & $\alpha$-Resorcylic acid & & $\mathrm{OH}$ & & $\mathrm{OH}$ & \\
\hline 14 & $\beta$-Resorcylic acid & $\mathrm{OH}$ & & $\mathrm{OH}$ & & \\
\hline 15 & $\gamma$-Resorcylic acid & $\mathrm{OH}$ & & & & $\mathrm{OH}$ \\
\hline 16 & Orsellinic acid & $\mathrm{OH}$ & & $\mathrm{OH}$ & & $\mathrm{CH}_{3}$ \\
\hline 17 & $p$-Orsellinic acid & $\mathrm{OH}$ & & $\mathrm{CH}_{3}$ & & $\mathrm{OH}$ \\
\hline 18 & o,o-Dimethylorsellinic acid & $\mathrm{CH}_{3} \mathrm{O}$ & & $\mathrm{CH}_{3} \mathrm{O}$ & & $\mathrm{CH}_{3}$ \\
\hline 19 & 3-Methylsalicylic acid & $\mathrm{OH}$ & $\mathrm{CH}_{3}$ & & & \\
\hline 20 & 4-Methylsalicylic acid & $\mathrm{OH}$ & & $\mathrm{CH}_{3}$ & & \\
\hline 21 & 6-Methylsalicylic acid & $\mathrm{OH}$ & & & & $\mathrm{CH}_{3}$ \\
\hline 22 & Everninic acid & $\mathrm{OH}$ & & $\mathrm{CH}_{3} \mathrm{O}$ & & $\mathrm{CH}_{3}$ \\
\hline 23 & Olivetolic acid & $\mathrm{OH}$ & & $\mathrm{OH}$ & & $\mathrm{C}_{5} \mathrm{H}_{11}$ \\
\hline
\end{tabular}

Table 2. The structure of hydroxycinnamic acids. The table represents the functional groups of aromatic ring.<smiles>[R]c1cc(/C=C/C(=O)O)c([R])c([R2])c1[R3]</smiles>

\begin{tabular}{clllll}
\hline Number & Hydroxycinnamic Acids & $\mathbf{R}_{\mathbf{1}}$ & $\mathbf{R}_{\mathbf{2}}$ & $\mathbf{R}_{\mathbf{3}}$ & $\mathbf{R}_{\mathbf{4}}$ \\
\hline $\mathbf{2 4}$ & o-Coumaric acid & $\mathrm{OH}$ & & & \\
$\mathbf{2 5}$ & m-Coumaric acid & & $\mathrm{OH}$ & $\mathrm{OH}$ & \\
$\mathbf{2 6}$ & p-Coumaric acid & & $\mathrm{OH}$ & \\
$\mathbf{2 7}$ & Ferulic acid & $\mathrm{CH}_{3} \mathrm{O}$ & $\mathrm{OH}$ & $\mathrm{OH}$ \\
$\mathbf{2 8}$ & 5-Hydroxyferulic acid & & $\mathrm{CH}_{3} \mathrm{O}$ & $\mathrm{OH}$ & \\
$\mathbf{2 9}$ & Isoferulic acid & $\mathrm{OH}_{3}$ & $\mathrm{CH}_{3} \mathrm{O}$ & $\mathrm{CH}_{3} \mathrm{O}$ \\
$\mathbf{3 0}$ & Sinapic acid & $\mathrm{CH}_{3} \mathrm{O}$ & $\mathrm{OH}$ & \\
$\mathbf{3 1}$ & Caffeic acid & $\mathrm{OH}$ & $\mathrm{OH}$ & \\
$\mathbf{3 2}$ & Umbellic acid & & $\mathrm{OH}$ & \\
\hline
\end{tabular}


The structure of phenolic acids defined by the position and number of methoxy and hydroxy groups attached to the aromatic ring contribute to their antioxidant or anti-radical scavenging properties $[34,35]$. These bioactive compounds form phenoxyl radicals, whereas the hydroxyl groups help to stabilise them [36]. Subsequently, these phenoxyl radicals can positively contribute to the neutralisation of toxic free radicals in the human body. The more hydroxy and methoxy groups are bonded to the benzene ring, the better the determination of the radical scavenging properties [35], as well as the indirectly attached carboxyl group (e.g., $-\mathrm{CH}=\mathrm{CH}-\mathrm{COOH}$ ) [37]. The radical scavenging activities decrease in the following order: gallic $>$ gentisic $>$ syringic $>$ caffeic $(31)>$ protocatechuic $(\mathbf{1 0})>$ sinapic (30) $>$ ferulic (27) $>$ isoferulic (29) $>$ vanillic $>p$-coumaric $>o$-coumaric (24) $>m$-coumaric (25) $>$ salicylic $>p$-hydroxybenzoic (1) acid [35]. The content of phenolic acids and other phenolic compounds in the extracts is proportional to the free radical scavenging activity [34,38]. Therefore, the synergistic interactions between phenolic acids [39] or the other compounds influence the final antioxidant properties - the total phenolic content leads to higher antioxidant activities [39-41].

\section{Phenolic Acids in Plants}

\subsection{Biosynthesis}

Phenolic acids are generated from aromatic amino acids produced via the shikimate pathway (Figure 1) [42]. Here, the shikimic acid is converted into L-phenylalanine through a chorismic acid intermediate. The L-phenylalanine is converted into $p$-coumaric, salycilic, and $p$-hydroxybenzoic acids, which serve as precursors for other derivatives of phenolic acids. The hydroxylation and methylation of their aromatic ring result in biosynthesis of other hydroxycinnamic acids (e.g., ferulic and caffeic acids) or hydroxybenzoic acids (e.g., protocatechuic and $p$-hydroxybenzoic acids) [43].

In plants, enzymes involved in the shikimate pathway are localised in plastids (chloroplasts) [44]. Here, the phenylalanine, as well as chorismic, salicylic, and gallic acids, are synthesised [45,46], whereas other hydroxycinnamic and hydroxybenzoic acids are synthesised in the cytosol [47]. It is thought that hydroxybenzoic acids can be produced from structurally analogous hydroxycinnamic acids in coenzyme A (CoA) dependant ( $\beta$-oxidative) or CoA-independent (non- $\beta$-oxidative) pathways or the combination of both them [48-52], which has been determined as occurring in peroxisomes [47] and mitochondria [53]. However, salicylic acid can also be synthesised in a few other ways: directly from either benzoic acid by benzoic acid 2-oxygenase or isochorismate by isochorismoyl-glutamate synthase and through the spontaneous or non-spontaneous (by isochorismoyl-glutamate A pyruvoyl-glutamate lyase) splitting of the isochorismoyl-glutamate A [54,55]. It has been observed that the concentration of salicylic acid in the cell usually depends on the isochorismate availability [56]. The conversion of salicylic acid into gentisic acid is catalysed by salicylic acid hydrogenase, with hypogallic (9) acid also produced in the reaction [57]. Isomers of $p$-coumaric acid are synthesised in plants in low amounts.

The biosynthesis of $o$-coumaric and $p$-coumaric acids co-occurs at microsomal membranes and is catalysed by cinnamic acid hydroxylases [58]. $m$-Coumaric acid could also be synthesised in small quantities from $m$-tyrosine that is produced from L-phenylalanine by radical hydroxylation under conditions of oxidative stress [59] or through direct hydroxylation, potentially involving the activity of cytochrome P450 enzyme, with the latter reported in Festuca rubra [60,61]. It is unknown if $m$-hydroxybenzoic (3) and $m$-coumaric acids can be synthesised from benzoic or cinnamic acids in plants. Therefore, the following hydroxylation of $p$-coumaric acids by $p$-coumaric acid 2-hydroxylase produces umbellic acid (32), which spontaneously forms lactone after closure of lactone ring under neutral or acidic conditions [62].

Orsellinic (16) and olivetolic (23) acids can also by synthesised in plants. The plant type III poliketide synthases such as tetraketide synthase from Cannabis sativa and orcinol synthase Rhododendron dauricum are involved in the biosynthesis of olivetolic and orsellinic acids as acetate-derived aromatic tetraketides, respectively [63]. 
(A)

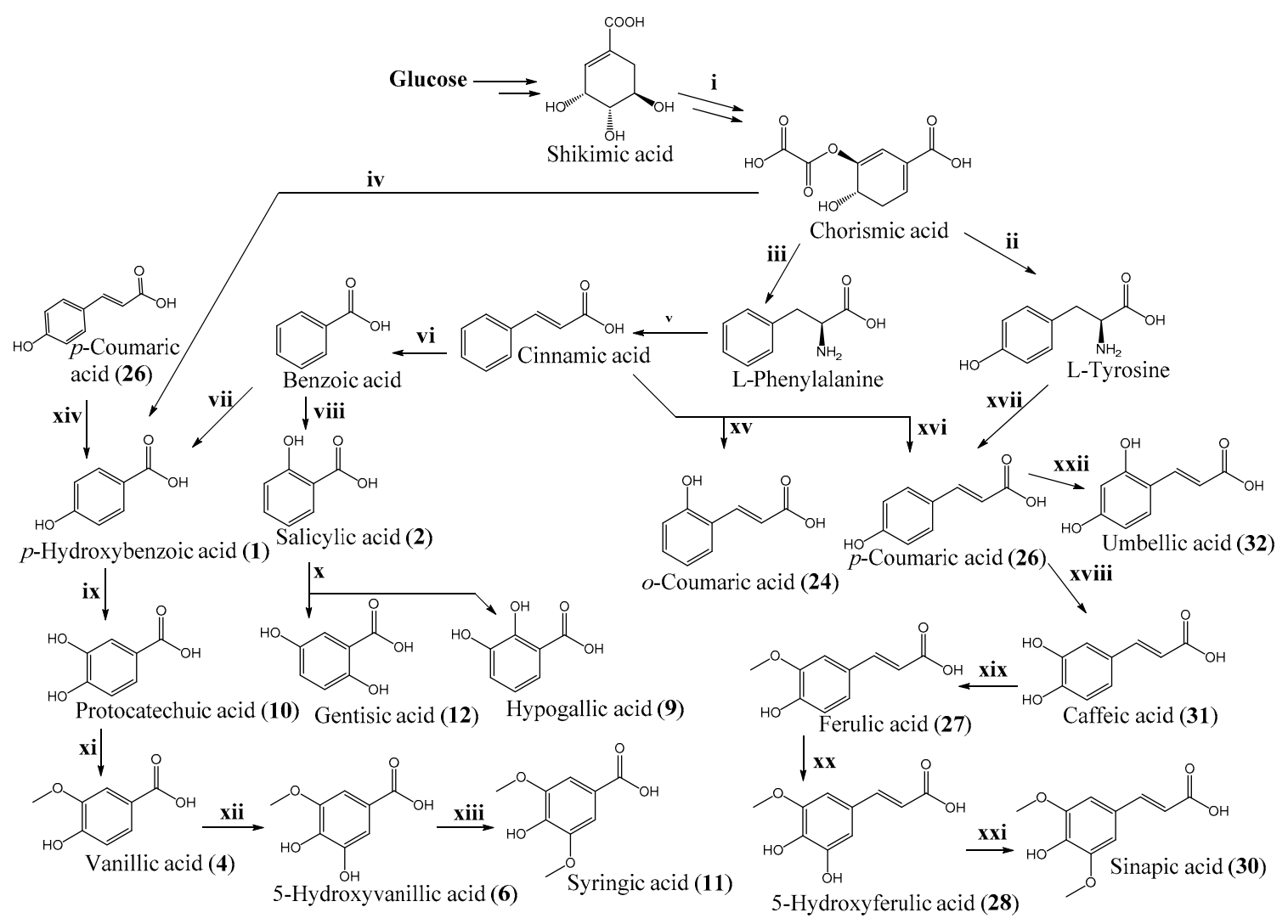

(B)

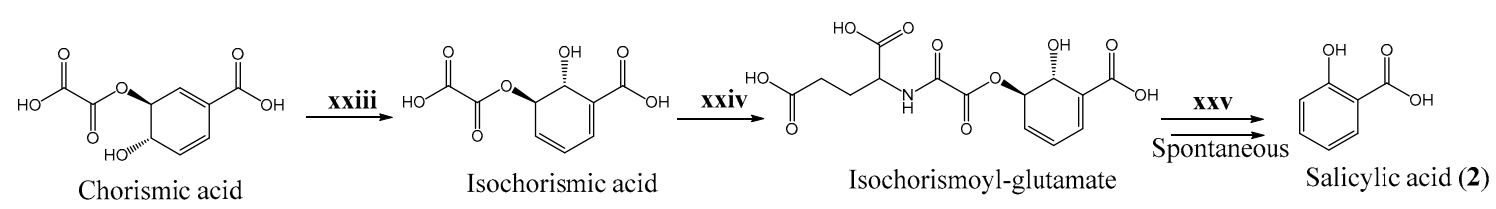

(C)

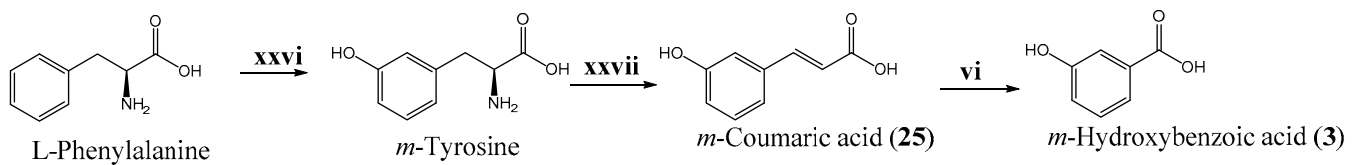

Figure 1. General scheme for the phenolic acid biosynthesis through the shikimate pathway (A), salicylic acid biosynthesis from isochorismate (B), and $m$-coumaric acid biosynthesis (C). Enzymes involved in the reactions: (i) shikimate kinase, 5-enolpyruvylshikimate-3-phosphate synthase and chorismate synthase; (ii) chorismate mutase, prephenate dehydrogenase; (iii) chorismate mutase, prephenate aminotransferase, arogenate dehydratase; (iv) chorismate-pyruvate lyase; (v) L-phenylalanine ammonia lyase (PAL); (vi) oxidase (or presumed $\beta$-oxidation); (vii) benzoic acid 4-hydroxylase; (viii) benzoic acid 2-hydroxylase; (ix) 4-hydroxybenzoic acid 3-hydroxylase; (x) salicylic acid 3-hydroxylase ( $\mathrm{S3H}$ ); (xi) protocatechuic acid 3-O-methyltransferase; (xii) vanillic acid 5-hydroxylase; (xiii) vanillic acid 5-O-methyltransferase; (xiv) 4-hydroxybenzaldehyde synthase and 4-hydroxybenzaldehyde dehydrogenase; (xv) cinnamic acid 2-hydroxylase; (xvi) cinnamic acid 4-hydroxylase; (xvii) tyrosine ammonia lyase (TAL); (xviii) p-coumaric acid 3-hydroxylase; (xix) caffeic acid 3-O-methyltransferase; (xx) ferulic acid 5-hydroxylase; (xxi) caffeic/5-hydroxyferulic acid O-methyltransferase (COMT); (xxii) p-coumaric acid 2-hydroxylase; (xxiii) isochorismate synthase (ICS); (xxiv) isochorismoyl-glutamate synthase (IGS); (xxv) isochorismoyl-glutamate A pyruvoyl-glutamate lyase (IPGL); (xxvi) cytochrome P450; (xxvii) tyrase. 
In plants, phenolic acids are found in free, conjugated forms (as aglycones) and in bound forms that are attached to the cell walls [32,64]. Naturally occurring compounds such as hydroxy fatty acids, terpene alcohols, lignin, triterpenoids, or glucose can form ester or ether bonds with phenolic acids [65]. The soluble conjugates of phenolic acids are usually stored in the storage vacuoles, which may occupy up to $90 \%$ of the cell volume [66].

\subsection{The regulation of Phenolic Acid Biosynthesis}

The response to biotic stress can activate systemic acquired resistance (SAR) gene expression due to pathogen attack, or the interaction with beneficial microorganisms can activate the immunity system of the plant (induced systemic resistance (ISR)) [67]. The pathogen attacks cause biotic stress to plants, which results in the production of various reactive oxygen containing species (oxygen, hydroxyl radicals, hydrogen peroxide, superoxide molecules; ROS) and nitric oxide (NO), which are the most active in the alkaline $\mathrm{pH}$, which results in the rise of cytosolic calcium ion concentration and closure of stomata $[68,69]$.

The formed ROS radicals and NO result in the production of azelaic acid via the cleavage of double bond (C9) of unsaturated C18 fatty acids [70]. Azelaic acid induces the SAR genes, and the production of salicylic acid occurs when the isochorismate synthase 1 (ICS1) gene which is controlled by several transcription factors such as NAC transcription factor-like 9 (NTL9) and CCA1 hiking expedition (CHE), is activated [71]. Then, the synthesis of other metabolites is also activated, which leads to plant health improvements and acquired resistance. Produced salicylic acid can be deactivated by methylation and conversion into 2-methyl salicylic acid via the mediation of salicylic acid methyltransferase 1 (SAMT1), and the activation (the conversion to salicylic acid) of the latter compound is mediated by methyl salicylate esterase of salicylic acid-binding protein 2 (SABP2) [72,73].

In the interaction with beneficial microorganisms, the induced systemic resistance (ISR) system is regulated by several phytohormones such as salicylic acid, jasmonic acid, and ethylene [74]. Salicylic acid is an antagonist for jasmonic and ethylene, and their cross-talk is regulated by suppression of different transcription factors [74-77]. The plant response to this interaction leads to the strengthening of cell walls, closure of stomata, and other secondary metabolite production, or this response can be similar to pathogen attack [67].

The abiotic stress in plants results in the decline of energy supply because of inhibition of energy-releasing reactions and photosynthesis in chloroplasts [78]. The plant stress hormone abscisic acid is involved in all these regulations, and it is responsible for osmotic stress tolerance and plant water balance [79]. However, ROS, NO, and lipid molecules are also involved in the response of plants to abiotic stress, and activate induced systemic resistance (ISR) of plants.

\subsection{Biotic and Abiotic Stress}

The accumulation of both hydroxybenzoic and hydroxycinnamic acids has been observed as being elevated after treatment with fungal or bacterial pathogens. For example, gallic, syringic, $p$-coumaric, salicylic, and sinapic acids are accumulated in peas raised from seeds treated with Trichoderma harzianum, Bacillus subtilis, and Pseudomonas aeruginosa [80]. The produced amount of different phenolic acids varies depending on the pathogen.

There are several abiotic stress factors: salinity, metal ions, light, water scarcity, wounding, or elicitor treatment. The accumulation of hydroxybenzoic acids results from salinity, treatment with a metal ion, or UV light [81-83]. Wounding stress also activates the production of phenolic acid (especially ferulic acid) derivatives, and their concentration can be increased up to 100\% [84]. The higher increase in the concentration of these compounds is obtained with a combination of wounding with hyperoxia, and chemical substances (elicitors) such as ethylene or methyl jasmonate $[84,85]$. Water deficit results in hydroxybenzoic acid biosynthesis [86]. The illumination by light with wavelengths less than $360 \mathrm{~nm}$ causes the isomerisation reaction of glucosides-bound o-hydroxycinnamic acid from trans to cis forms in leaves [87]. 


\subsection{Factors Influencing the Amount of Accumulated Phenolic Acids}

Several factors influence the accumulated and determined content of phenolic acids before or after the collection of raw materials. The seasonality, different cultivars, planting location, geographical area, agricultural conditions, part of the plant used (leaves, flowers, or whole plant), sample dryness (fresh or dried sample), and type of the plant may have an effect on the recovered amount of secondary metabolites including phenolic acids [88-91]. After collection of raw material, the drying temperature, storage temperature, and time, as well as the extraction method, the solvent used, and the number of extraction cycles, determines the final amount of obtained phenolic acids [92-94]. Notably, the storage temperature and time may lead to an increased concentration of total phenolic acids [93], whereas the increased oven-drying temperature leads to the decreased concentration of the same compounds [92].

\section{Production and Extraction of Phenolic Acids from Plants and Algae}

The concentrations of phenolic acids can vary significantly in various plants and algae. Crops, cereals, fruits and vegetables, oilseeds, herbs and spices, teas, and coffee are the major sources of phenolic acids. The highest amounts of these compounds obtainable from plants and algae are presented in Table 3. The quantity of free phenolic acids can range from micrograms to milligrams per gram of dry weight of plant tissue. The content of these compounds differs between sources. In the hydroxybenzoic acid group, the highest yields of amounts have been reported for gallic, gentisic, and syringic acids. The highest content of gallic acid varied between 1485-30603 $\mu \mathrm{g} / \mathrm{g}$ dry weight (DW) in pulp from Byrsonima ligustrifolia fruits, followed by the diatom (Odontella sinensis; $9489 \mu \mathrm{g} / \mathrm{g}$ DW) and clove (Eugenia caryophylata Thunb.) leaves $(7385 \mu \mathrm{g} / \mathrm{g}$ DW). The amount of gentisic acid has been reported to range from 120 to $8600 \mu \mathrm{g} / \mathrm{g}$ DW, with the highest amount extracted from lavender (Lavandula officinalis L.) flowers, followed by bitter melon (Momordica charantia L.) fruits (5910 $\mu \mathrm{g} / \mathrm{g})$. The highest concentration of syringic acid was found in blueberry (Vaccinium. myrtillus L.) fruits (5627.47 $\mu \mathrm{g} / \mathrm{g} \mathrm{DW})$. In the hydroxycinnamic acid group, the highest yields were achieved for caffeic, ferulic, and $p$-coumaric acids. The amount of caffeic acid ranged from 537 to $17400 \mu \mathrm{g} / \mathrm{g}$ DW, with the highest amount extracted in roasted coffee beans, followed by tansy (Tanacetum vulgare L.) leaves ( $8940 \mu \mathrm{g} / \mathrm{g} \mathrm{DW}$ ), and potato (Solanum tuberosum L.) peels (3320 $\mu \mathrm{g} / \mathrm{g}$ DW). Amounts between 116 and $7000 \mu \mathrm{g} / \mathrm{g}$ DW of ferulic acid were detected in white onion (Allium cepa L.) outer layers, baru (Dipteryx alata Vog.) nuts, hyssop (Hyssopus officinalis L.) herbs, mate (Ilex paraguariensis St. Hil.) leaves, and the bran and aleurone of wheat (Triticum aestivum L.). The content of $p$-coumaric acid varied between 2898-5265 $\mu \mathrm{g} / \mathrm{g}$ DW in pulp from Byrsonima ligustrifolia fruits. Chokeberry (Aronia melonocarpa L.) fruits exhibited the highest amount of $p$-coumaric acid $(4020 \mu \mathrm{g} / \mathrm{g}$ fresh weight $(\mathrm{FW})$. The change in extraction method, solvents, and the application of hydrolysis may increase the determined phenolic acid concentrations in each plant. 
Table 3. Yields of free phenolic acids extracted from plants.

\begin{tabular}{|c|c|c|c|c|c|c|}
\hline Phenolic Acid & Plant Type and Part & Extraction Method & Solvent & $\begin{array}{l}\text { Hydrolysis } \\
\text { Applied *a }\end{array}$ & $\begin{array}{c}\text { Yield ( } \mu \mathrm{g} / \mathrm{g} \\
\text { Dry Weight) }\end{array}$ & Reference \\
\hline \multirow{4}{*}{$p$-Hydroxybenzoic acid (1) } & Maya nut (Brosimum. alicastrum) & Ultrasound-assisted extraction & Methanol-acetic acid & Alkaline & 326.2 & [95] \\
\hline & Pulp from Byrsonima ligustrifolia fruits & Ultrasound-assisted extraction & Methanol, acetone & Alkaline, acidic & $1000-2820$ & [96] \\
\hline & Raspberry (Rubus idaeus L.) fruits & Percolation & Water-ethyl acetate & Acidic, alkaline & 709.62 & [32] \\
\hline & Strawberry (Fragaria ananassa) fruits & Ultrasound-assisted extraction & Methanol with butylated hydroxyanisole $-10 \%$ acetic acid & Acidic & $44-63^{\mathrm{b}}$ & [97] \\
\hline \multirow[t]{2}{*}{$m$-Hydroxybenzoic acid (3) } & Melon (Cucumis melo L.) peels & Maceration & Ethanol-water & - & 334.5 & [98] \\
\hline & Mangosteen (Garcinia mangostana L.) fruit peel & Maceration & Water-methanol & - & 0.07 & [99] \\
\hline \multirow[t]{2}{*}{ Salicylic acid (2) } & Wheat (Triticum aestivum $\mathrm{L}$.) straws & Maceration & Water & - & 190.1 & [100] \\
\hline & Fresh red quinoa (Chenopodium quinoa) leaves & Accelerated solvent extraction & Methanol-water & - & 0.48 & [92] \\
\hline \multirow[t]{3}{*}{ Vanillic acid (4) } & Blueberry (Vaccinium myrtillus L.) leaves & Ultrasound-assisted extraction & Methanol-formic acid, acetone-formic acid & 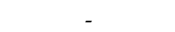 & 1156.80 & [88] \\
\hline & Maya nut (Brosimum. alicastrum) & Sonication & Methanol-acetic acid & Alkaline & 103 & [95] \\
\hline & Grape (Citrus paradisi) pomace & Ultrasound-assisted extraction & Ethanol-water & - & 86 & [101] \\
\hline Isovanillic acid (5) & Melon (C. melo L.) peels & Maceration & Ethanol-water & - & 237 & [98] \\
\hline \multirow{7}{*}{ Gallic acid (8) } & Microalgae (Ophiocordyceps sinensis) & Maceration & Methanol & - & 9489 & [102] \\
\hline & Clove (Eugenia caryophylata Thunb.) leaves & Maceration & Methanol-water & 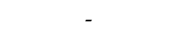 & 7385 & [103] \\
\hline & Black tea (Clonorchis sinensis) leaves & Percolation & Ethanol-water & & 6550 & [104] \\
\hline & Chinese olive (Canarium album) peel & Maceration & Methanol-acetic acid-water mixture & & $3696^{\mathrm{b}}$ & [105] \\
\hline & Pulp from B. ligustrifolia fruits & Ultrasound-assisted extraction & Methanol, acetone, acetic acid & Acidic, alkaline & $1485-30603$ & [96] \\
\hline & Potatoes (Solanum tuberosum $\mathrm{L}$.) peels & Maceration, ultrasound-assisted extraction & Ethanol-acetic acid & Acidic & 2330 & [106] \\
\hline & Raspberry (R. idaeus L.) fruits & Maceration & Water & Acidic, alkaline & 1669 & [32] \\
\hline \multirow[t]{6}{*}{ Protocatechuic acid (10) } & Chia (Salvia hispanica L.) seeds & Maceration & Methanol-water & & 759 & [107] \\
\hline & Cocao (Theobroma cacao) powder & Maceration & Methanol, acetic acid, butylated hydroxyanisole & Acidic, alkaline & 400 & [97] \\
\hline & Red onion (Allium cepa L.) outer layer & Maceration & Methanol-water & 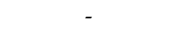 & 354 & [108] \\
\hline & Araticum (Annona crassiflora Mart.) fruit peels & Ultrasound-assisted extraction & Methanol-acetone-water & & 318 & [109] \\
\hline & Hyssop (Hyssopus officinalis L.) herb & Maceration & Methanol & - & 310 & [110] \\
\hline & Star anise (Illicium verum) fruits & Maceration & Ethanol & & 209.7 & [111] \\
\hline \multirow[t]{4}{*}{ Syringic acid (11) } & Blueberry (V. myrtillus L.) fruits & Ultrasound-assisted extraction & Methanol-formic acid, acetone-formic acid & Acidic & 5627.47 & [88] \\
\hline & Cashew (Anacardium occidentale L.) nut testa (defatted) & Maceration & Ethanol-water & Acidic, alkaline & 2507 & [112] \\
\hline & Lemon balm (Melissa officinalis L.) plants & Percolation & Methanol-water & & 540.8 & [113] \\
\hline & Raspberry (R. idaeus L.) fruits & Percolation & Water-ethyl acetate & Acidic, alkaline & 113.41 & [32] \\
\hline \multirow{3}{*}{ Gentisic acid (12) } & Lavender (Lavandula officinalis L.) flowers & Maceration & Methanol & - & 8600 & [110] \\
\hline & Bitter melon (Momordica charantia L.) fruits & Accelerated solvent extraction & Water & & 5910 & [114] \\
\hline & Strawberry (Fragaria ananassa L.) fruits & Percolation & Water-ethyl acetate & Acidic, alkaline & 120 & [32] \\
\hline \multirow{2}{*}{ 4-Methylsalicylic acid (20) } & Blueberry (V. myrtillus L.) fruits & Maceration & Sodium carbonate solution & Acidic & 24 & [115] \\
\hline & Beans (Vicia faba L.) & Maceration & Sodium carbonate solution & Acidic & 0.92 & [115] \\
\hline \multirow{2}{*}{ 3-Methylsalicylic acid (19) } & Beans (V. faba L.) & Maceration & Sodium carbonate solution & Acidic & 4.37 & [115] \\
\hline & Blueberry (V. myrtillus L.) fruits & Maceration & Sodium carbonate solution & Acidic & 0.8 & [115] \\
\hline \multirow{4}{*}{$p$-Coumaric acid (26) } & Chokeberry (Aronia melonocarpa L.) fruits & Ultrasound-assisted extraction & Acidic water-ethanol & & $4020^{\mathrm{b}}$ & [116] \\
\hline & Pulp from B. ligustrifolia fruits & Ultrasound-assisted extraction & Methanol, acetone, acetic acid & Alkaline, acidic & $2898-5265$ & [96] \\
\hline & Leaves of walnut tree (Juglans regia L.) & Ultrasound-assisted extraction & Methanol & , & 1250 & [117] \\
\hline & Strawberry (Fragaria ananassa L.) fruits & Maceration & Water & Acidic, alkaline & 1108 & [32] \\
\hline \multirow{3}{*}{$o$-Coumaric acid (24) } & Leaves of rubber vine (Conradina grandiflora) & Maceration & Methanol & & 45.55 & [118] \\
\hline & $\begin{array}{l}\text { Leaves of moringa (Moringa oleifera L.) } \\
\text { (M) }\end{array}$ & Maceration & Methanol, ethanol, ethyl acetate, water, and acetone & - & 37 & [119] \\
\hline & Barley (Hordeum vulgare L.) straws & Maceration & Water & - & 1.8 & [100] \\
\hline$m$-Coumaric acid (25) & Rice (Labelle) hull & Maceration & Methanol-water & - & 432 & [120] \\
\hline
\end{tabular}


Table 3. Cont.

\begin{tabular}{|c|c|c|c|c|c|c|}
\hline Phenolic Acid & Plant Type and Part & Extraction Method & Solvent & $\begin{array}{l}\text { Hydrolysis } \\
\text { Applied *a }\end{array}$ & $\begin{array}{c}\text { Yield ( } \mu \mathrm{g} / \mathrm{g} \\
\text { Dry Weight) }\end{array}$ & Reference \\
\hline \multirow{7}{*}{ Caffeic acid (31) } & Melon (C. melo L.) peels & Maceration & Ethanol-water & - & 199.1 & [98] \\
\hline & Barley (Hordeum vulgare L.) straws & Maceration & Water & - & 3.1 & [100] \\
\hline & Leaves of rubber vine (C. grandiflora) & Maceration & Methanol & - & 1.02 & [118] \\
\hline & Roasted coffee beans ${ }^{c}$ & Maceration & Hot water & - & 17,400 & [97] \\
\hline & Leaves of tansy (Tanacetum vulgare L.) & Ultrasound-assisted extraction & Methanol & 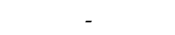 & 8940 & [117] \\
\hline & Potatoes (S. tuberosum L.) peels & Maceration, ultrasound-assisted extraction & Ethanol-acetic acid & Acidic & 3320 & [106] \\
\hline & Basil (Ocimum basilicum L.)herb & Maceration & Methanol & . & 2600 & [110] \\
\hline \multirow{6}{*}{ Ferulic acid (27) } & Mate (Ilex paraguariensis St. Hil.) leaves & Percolation & Ethanol-water & - & 760 & [104] \\
\hline & Blackcurrant (Ribes nigrum L.) fruits & Maceration & Water & Acidic, alkaline & 537 & [32] \\
\hline & Wheat (T. aestivum L.) aleurone & Maceration & Sodium hydroxide solution in water & $\begin{array}{l}\text { Alkaline } \\
\text { A }\end{array}$ & $>7000$ & [121] \\
\hline & Wheat (T. aestivum L.) bran & Maceration & Methanol-water & - & 2020 & [122] \\
\hline & Mate (I. paraguariensis St.Hil.) leaves & Percolation & Ethanol-water & - & 1360 & [104] \\
\hline & Hyssop (Hyssopus officinalis L.) herbs & Maceration & Methanol & - & 460 & [110] \\
\hline \multirow{5}{*}{ Sinapic acid (30) } & Baru (Dipteryx alata Vog.) nuts & Maceration & Methanol-hydrochloric acid solution & - & 454 & [123] \\
\hline & White onion (A. сера L.) outer layer & Maceration & Methanol-water & - & 116 & [108] \\
\hline & Mate (I. paraguariensis) leaves & Percolation & Ethanol-water & - & 1870 & [104] \\
\hline & Defatted canola (Brassica napus L.) seeds & Ultrasound-assisted extraction & Methanol-water & - & $590^{\mathrm{b}}$ & [94] \\
\hline & Strawberry $(F$. ananassa L.) fruits & Maceration & Water & Acidic & 445 & [32] \\
\hline
\end{tabular}

$* a$-hydrolysis applied results in the increased concentration of free phenolic acids; ${ }^{b}$-on fresh matter; ${ }^{c}$-recalculated from coffee brew to coffee beans. 


\subsection{Cereals}

Crops contain various useful and bioactive compounds, including phenolic acids [92]. The most abundant phenolic acid in cereals is ferulic acid, consisting of up to $90 \%$ of total phenolic acid content in wheat, spelt, buckwheat, and oats [124]. It can be present at up to $2 \mathrm{mg} / \mathrm{g}$ in wheat bran and up to $7.98 \mathrm{mg} / \mathrm{g}$ in wheat aleurone [122,125]. Therefore, $p$-coumaric, ferulic, vanillic, and $p$-hydroxybenzoic acids are found in cereal grain, and the highest concentration of these compounds is located in husks or glume [124]. Changes in bound and soluble phenolic acids also occur during the development of wheat grain. The concentration of soluble hydroxycinnamic acids (ferulic acid, $p$-coumaric, and sinapic acids) steadily decrease, and the insoluble fraction increase during grain development, with these changes possibly influencing the properties of the cell wall and the whole grain [126].

\subsection{Seeds and Oilseeds}

Seeds such as chia, sunflower seeds, or flaxseeds are rich in bound phenolic acids $(>10 \mathrm{mg} / \mathrm{g})$ where the dominant acids are ferulic, $p$-coumaric, and caffeic acids, as well as protocatechuic and p-hydroxybenzoic acids and their derivatives (glucosides, chlorogenic acids, ferulic acid dehydrotrimers, monoacyl- and diacylquinic acids) [107,127,128]. However, monoacylquinic acids are the major compounds, consisting of bound caffeic and p-coumaric acids [127], which can be hydrolysed into their corresponding acids. Therefore, the free phenolic acids (gallic, sinapic, protocatechuic) were found in high concentrations only in canola seeds $(52 \mathrm{mg} / \mathrm{g}$ defatted material, or up to $31 \mathrm{mg} / \mathrm{g}$ dry weight) $[129,130]$. Therefore, the seeds (sunflower seeds, chia) extracts contain the isomers of phenolic acids (cis- and trans-ferulic acids, and $p-, o-, m$-coumaric acids) $[107,127]$.

\subsection{Fruits and Berries}

One of the best sources of soluble phenolic acids is fruits and berries, which also contain free forms of these compounds [32]. Berries contain a concentration of soluble phenolic acids that is higher than fruits. The total amount of soluble phenolic acids is determined in plum, some varieties of apples, and cherry (up to $0.28 \mathrm{mg} / \mathrm{g}$ ), but in rowanberry, chokeberry, blueberry, sweet rowanberry, and saskatoon berry, their concentrations reach up to $0.59-1.03 \mathrm{mg} / \mathrm{g}$ fresh weight [97]. Generally, berries and fruits contain high concentrations (up to $750 \mu \mathrm{g} / \mathrm{g}$ fresh weight for single phenolic acid) of gallic, ferulic, protocatechuic, caffeic, $p$-hydroxybenzoic, $p$-coumaric, sinapic, and chlorogenic (the source of bound caffeic acid) acids [32,97,131]. Therefore, trace amounts of 3- and 4-methyl salicylic acids (19 and 20) are found in blueberries [115].

In fruits, the concentration of phenolic acids depends on the part of fruit analysed. These compounds are usually located in the rind and peels, for example, the peel and rind of mangosteen fruit are rich in protocatechuic acid, but the peels of apples contain lower levels of phenolic acids than the whole fruit $[97,99]$. For berries, the change in concentration (increase or decrease) of phenolic acids depends on the maturation stages for a particular plant [96,132].

\subsection{Vegetables}

Vegetables contain more hydroxycinnamic acids than hydroxybenzoic acids. Sinapic acid is abundant in the Brassicaceae family (up to $79 \%-84 \%$ of all phenolic acids). In other vegetables such as red cabbage, carrots, lettuce, and artichoke, the predominant hydroxycinnamic acid is ferulic acid, with the total amount of phenolic acids reaching up to $0.52 \mathrm{mg} / \mathrm{g}$ fresh weight [81,133]. However, potatoes contain high amounts of gallic, $p$-coumaric, chlorogenic, and caffeic acids [134]. On the other hand, gallic and protocatechuic acids (hydroxybenzoic acids) are dominant in onions, and 3- and 4-methyl salicylic acids are found in beans [108,115].

The different layers of vegetables (onions, lettuce) accumulate diverse amounts of phenolic acids in which concentration depends on the plant type [135]. Peels or outer layers of roots contain the 
largest amount of phenolic acids. Notably, the treatment of vegetables by boiling, baking, or pickling may reduce the concentration of phenolic acids $[133,136]$.

\subsection{Nuts}

Gallic, $p$-hydroxybenzoic, protocatechuic, and $p$-coumaric acids are the major bound phenolic acids found in nuts $[112,123,137,138]$. They are mainly localised in the protective skin [139]. The abundance of different phenolic acids depends on the part of the nut, for example, cashew kernels contain syringic and $p$-coumaric acids, but their testa is rich in gallic, syringic, and p-coumaric acids [112].

Roasting of nuts increases the content of gallic acid, which is released from hydrolysable tannins, but it may reduce the content of other phenolic acids [112,123]. The long term storage for different types of nuts also influences the phenolic acid content- $p$-hydroxybenzoic acid content increased up to 18 -fold in almond skin while it did not influence the concentration of $p$-coumaric and $p$-hydroxybenzoic acids in peanuts $[140,141]$.

\subsection{Spices and Medicinal Herbs}

Spices (basil, rosemary, star anise, chili pepper, bay, savory, etc.) used for culinary purposes are usually from the following families: Lamiaceae, Lauraceae, Brassicaceae, Apiaceae, Labiateae, Schisandraceae, Myrtaceae, Solanaceae, Piperaceae, and Cinnamomum. The same type of herbs can also be used in medicinal applications, but these must meet the specific quality standards [142]. The most popular medicinal herbs are from Lamiaceae and Asteraceae families, containing a high amount of phenolic acids and other phenolic compounds and showing better antioxidant properties when compared to other families, for example, the Apiaceae family [142]. Therefore, caffeic acid or the derivatives of this acid (rosmarinic or chlorogenic acids) are abundant in Lamiaceae, Labiatae, Lauraceae, and Myrtaceae families $[103,110,143]$.

\subsection{Tea, Cacao, and Coffee}

The water extracts of cacao, tea leaves, and coffee are commonly used beverages in the human diet on an everyday basis. In coffee (roasted and unroasted), the major phenolic acids are derivatives of chlorogenic acid $[37,144]$. The roasting of coffee beans reduces phenolic acid content. The coffee brew from green beans contains up to $209 \mathrm{mg} / 100 \mathrm{~g}$, and the roasting reduces the amount of phenolic acids by almost $2-4$ times $[37,144]$. However, cocoa beverages contain a low amount of phenolic acids due to dilution, although cacao powder is rich in protocatechuic, vanillic, and syringic acids [97]. In teas such as black, mate, green, and oolong teas, the major phenolic acids are also chlorogenic acid derivatives [145]. Therefore, these teas (except mate) contain a huge amount of gallic acid (4.97-6.55 mg/g), but only mate tea contains caffeic, ferulic, and sinapic acids $(0.76-1.87 \mathrm{mg} / \mathrm{g})$ [104].

\subsection{Algae}

Gentisic, sinapic, caffeic, vanillic, gallic, ferulic, syringic, or $p$-hydroxybenzoic acids have been identified in the extracts of microalgae such as Chaetoceros calcitrans, Isochyrysis galbana, Skeletonema costatum, Odontella sinensis, Phaeodactylum tricornutum, and Saccharina japonica [102]. The highest total amount of these phenolic acids has been determined in O. sinensis (18.3 mg/g DW), where the dominant phenolic acid is gallic acid (9.5 mg/g DW).

\subsection{Extraction of Phenolic Acids from Agro-Industrial Waste}

Agro-industrial waste is composed of the organic residues that cannot be used for any purpose in their current state, and they are classified into several categories [146]. Agro-industrial residues are divided into industrial residues (e.g., peels of fruits and vegetables, oil cakes of soybean or other oilseeds, pomaces) and agricultural waste. Agricultural waste includes field-process residues remaining after crop harvesting (leaves, seedpods, stalks, or sterns), or they can be the residues of 
agricultural processing (straws, husks, bagasses, molasses, seeds, and roots). The amounts of each type of agro-industrial and agricultural waste (e.g., rice husk, apple pomace, citrus fruit processing residues) are generated in millions of metric tonnes per year worldwide [147]. These numbers show the huge importance of waste reprocessing to the value-added products for the utilisation of waste amounts.

Agro-industrial and agricultural waste contains mostly bound phenolic acids, which can be released after alkaline hydrolysis $[148,149]$. For the straws, techniques such as hydrothermal pretreatment are applied for enhanced release of bounded phenolic acids [150]. The amount of phenolic acids in an agro-industrial waste can reach up to a few percent of the raw material. For example, sugarcane bagasse contains up to $4.1 \%$ (or $41 \mathrm{mg} / \mathrm{g}$ ) of $p$-coumaric acid [148]. The concentration of phenolic acids varies in the different types of waste. For mangosteen fruit, the amounts of total phenolic acids vary from $6 \mathrm{mg} / \mathrm{kg}$ DW in aril to $70 \mathrm{mg} / \mathrm{kg}$ (peel) and $218 \mathrm{mg} / \mathrm{kg}$ in rind [99]. For araticum fruit, the accumulation of free phenolic acids is higher in peels than seeds [109]. However, agro-industrial waste contains more variety of phenolic acids, including isoferulic, isovanillic (5), hypogallic, and $\gamma$-resorcylic (15) acids [151-153]. In the extracts, hydroxycinnamic acids ( $p$-, $o$-coumaric, ferulic acids) can be found in both configuration as cis and trans stereoisomers, with the latter being the predominant form $[148,150]$.

\section{Production and Extraction of Phenolic Acids from Fungi}

Although plants are the primary source, phenolic acids are also abundant as secondary metabolites in fungi such as mushrooms and yeasts [64]. As in plants, similar factors contribute to the biosynthesis of phenolic acids in fungi.

\subsection{Mushrooms}

Wild or cultivated mushrooms are popular dietary ingredients, and they can also be used in medicinal applications [154,155]. Hydroxybenzoic acids ( $p$-hydroxybenzoic, protocatechuic, gallic, vanillic, and syringic acids), hydroxycinnamic acids ( $p$-coumaric, $o$-coumaric, ferulic, caffeic acids), and phenolic acids derivatives (e.g., ellagic acid, chlorogenic acid, rosmarinic acid) are found in the extracts of mushrooms [38,156-160]. Most species of mushrooms accumulate a smaller amount of phenolic acids when compared with plants. The exceptions are Ramaria botrytis, which is rich in protocatechuic acid (343 $\mu \mathrm{g} / \mathrm{g}$ DW) [156], and Agaricus brasiliensis, which contains high amounts (333-753 $\mu \mathrm{g} / \mathrm{g}$ DW) of $p$-hydroxybenzoic, gallic, and ferulic acids [34]. The highest amounts of phenolic acids obtained from mushrooms are presented in Table 4.

$\beta$-Resorcylic (14) and protocatechuic acids were the phenolic acids identified in mushrooms with higher activity against the majority of Gram-negative and Gram-positive bacteria [161]. Methicillin-resistant Staphylococcus aureus (MRSA) was inhibited by $\beta$-resorcylic, vanillic, syringic (minimum inhibitory concentration (MIC) is $0.5 \mathrm{mg} \mathrm{ml}^{-1}$ ) and $p$-coumaric (MIC $=1 \mathrm{mg} \mathrm{ml}^{-1}$ ) acids. The presence of carboxylic acid $(\mathrm{COOH})$, two hydroxyl $(\mathrm{OH})$ groups in para and ortho positions of the benzene ring, and also a methoxy $\left(\mathrm{OCH}_{3}\right)$ group in the meta position seems to be important for anti-MRSA activity [161]. 
Table 4. Phenolic acid distribution in various species of mushrooms.

\begin{tabular}{|c|c|c|c|c|c|}
\hline Phenolic Acid & Mushroom & Extraction Method & Solvent & Yield ( $\mu \mathrm{g} / \mathrm{g} D W)$ & Reference \\
\hline \multirow[t]{3}{*}{ Protocatechuic acid (10) } & Ramaria botrytis & Maceration & Methanol & 342.7 & [156] \\
\hline & Morchella esculent & Ultrasound-assisted extraction & Methanol & 17.15 & {$[41]$} \\
\hline & Ganoderma lucidum & Ultrasound-assisted extraction & Methanol & 3.01 & [41] \\
\hline \multirow[t]{4}{*}{ p-Hydroxybenzoic acid (1) } & Agaricus brasiliensis & Maceration & Ethanol-water & 332.76 & [34] \\
\hline & Agaricus silvicola & Maceration & Methanol & 238.7 & [156] \\
\hline & R. botrytis & Maceration & Methanol & 14.00 & [156] \\
\hline & G. lucidum & Ultrasound-assisted extraction & Methanol & 5.22 & {$[41]$} \\
\hline \multirow[t]{3}{*}{ Gallic acid (8) } & A. brasiliensis & Maceration & Ethanol-water & 491.89 & {$[34]$} \\
\hline & M. esculent & Ultrasound-assisted extraction & Methanol & 0.7818 & {$[41]$} \\
\hline & Rugiboletus extremiorientalis & Ultrasound-assisted extraction & Water & 0.03654 & {$[38]$} \\
\hline \multirow{4}{*}{$p$-Coumaric acid (26) } & A. silvicola & Maceration & Methanol & 45.72 & [156] \\
\hline & A. brasiliensis & Maceration & Ethanol-water & 24.47 & [34] \\
\hline & Agaricus bisporus (white) & Ultrasound-assisted extraction & Methanol-water mixture & 2.31 & [162] \\
\hline & G. lucidum & Ultrasound-assisted extraction & Methanol & 1.39 & {$[41]$} \\
\hline \multirow[t]{3}{*}{ Ferulic acid (27) } & A. brasiliensis & Maceration & Ethanol-water & 752.54 & [34] \\
\hline & M. esculent & Ultrasound-assisted extraction & Methanol & 0.075 & [41] \\
\hline & R. extremiorientalis & Ultrasound-assisted extraction & Water & 0.001 & [38] \\
\hline \multirow[t]{2}{*}{ Vanillic acid (4) } & G. lucidum & Ultrasound-assisted extraction & Methanol & 15.96 & [41] \\
\hline & R. extremiorientalis & Ultrasound-assisted extraction & Water & 0.0113 & [38] \\
\hline \multirow[t]{2}{*}{ Syringic acid (11) } & G. lucidum & Ultrasound-assisted extraction & Methanol & 2.34 & [41] \\
\hline & R. extremiorientalis & Ultrasound-assisted extraction & Water & 0.0016 & [38] \\
\hline Sinapic acid (30) & R. extremiorientalis & Ultrasound-assisted extraction & Water & 0.0022 & [38] \\
\hline Gentisic acid (12) & A. brasiliensis & Maceration & Ethanol-water & 27.73 & {$[34]$} \\
\hline
\end{tabular}




\subsection{Lichens}

Lichens are symbiotic associations of algae and fungi or cyanobacteria living in amongst the filaments of various fungi such as Trichoderma spp., Usnea, and Cladonia uncialis. The lichenising fungi have polyketide synthase gene clusters, which enable them to produce orsellinic acid and its derivatives [163-165]. However, they can also produce unique phenolic acids. For example, compounds identified in Usnea extracts include phenolic acids such as everninic acid (22), p-orsellinic acid (17), o,o-dimethylorsellinic acid (18), and 3-butyryl- $\beta$-resorcylic acid [165]. Other alkylated orsellinic acid derivatives ( $p$-orsellinic, ethyl-, propyl-, isobutyl, isopropyl-, and sec-butyl-orsellinates) were isolated from a Parmotrema tinctorum specimen [166], and these acids are specific to lichens.

Yeasts, as well as filamentous fungi, are usually used in fermentation processes, which are discussed below.

\section{Production of Phenolic Acids Using Non-Modified and Engineered Microorganisms}

\subsection{Biosynthesis of Phenolic Acids from Organic Compounds Using Non-Modified Microorganisms}

Natural microorganisms are capable of producing phenolic acids during assimilation and catabolism of other organic compounds (Table 5). For example, the biotransformation processes have been applied for the production of syringic acid from sinapic acid by Paecilomyces variotii [167]. Salicylic acid can be produced in high yields from naphthalene by Pseudomonas aeruginosa when the acidity of the medium is regulated by the addition of urea [168]. In addition, salicylic acid is produced in low yields from sucrose by Rubrivivax gelatinosus RASN4 strain isolated from rhizospheric soil of paddy fields [169]. The conversion of vanillic acid from ferulic acid (which is supplied as a pure compound or as an extract from pineapple peels) is performed by Paenibacillus lactis, Halomonas elognata, Aspergillus niger, and Sporotrichum thermophile [170-173]. The isolated Aspergillus spp. from moulds produces orsellinic acid also in less than 1\% yield using Sabauraud medium [174]. Gallic acid is produced from tannic acid by Kluyveromyces marxianus and Aspergillus fischeri $[175,176]$. The product yields in these processes reach more than $90 \%$. 
Table 5. The production of phenolic acids produced through biotransformation or fermentation using non-modified microorganisms.

\begin{tabular}{|c|c|c|c|c|c|}
\hline Product & Initial Concentration & Final Concentration or Yield & $\begin{array}{l}\text { Raw Material or } \\
\text { Substrate }\end{array}$ & Fungi/Bacteria & Reference \\
\hline$p$-Hydroxybenzoic acid (1) & $3.48 \pm 0.10 \mu \mathrm{g} / \mathrm{g}$ & $21.80 \pm 1.5 \mu \mathrm{g} / \mathrm{g}$ & $\begin{array}{l}\text { Hemicelluloses from } \\
\text { kidney bean extract }\end{array}$ & B. subtilis & [177] \\
\hline \multirow{3}{*}{ Salicylic acid (2) } & $6.2 \pm 1.8 \mathrm{mg} / \mathrm{g}_{\text {dry weight }}$ & $22.3 \mathrm{mg} / \mathrm{g}_{\text {dry weigt }}$ & Lignin from rice bran & R. oryzae & [178] \\
\hline & $0 \mathrm{~g} / \mathrm{L}$ & $\approx 15 \mathrm{~g} / \mathrm{L}$ & Naphtalene (2\%) & P. aeruginosa & [168] \\
\hline & $0 \mathrm{mg} / \mathrm{L}$ & $27.3 \mathrm{mg} / \mathrm{L}(0.13 \%)$ & $\begin{array}{l}\text { Sucrose }(80 \mathrm{mM} / \mathrm{L}) \text { from } \\
\text { RM2 medium }\end{array}$ & R. gelatinosus RASN4 & [169] \\
\hline \multirow[t]{4}{*}{ Gallic acid (8) } & $0 \mathrm{~g} / \mathrm{g}$ of biomass accumulated & $\begin{array}{l}7.35 \mathrm{~g} / \mathrm{g} \text { of biomass } \\
\text { accumulated }\end{array}$ & Tannic acid & A. fischeri MTCC 150 & {$[175]$} \\
\hline & $0 \%$ & $94.8 \%$ & Tannic acid & $\begin{array}{l}\text { R. oryzae (RO IIT RB-13, NRRL 21498) } \\
\text { and A. foetidus (GMRB013 MTCC 3557) }\end{array}$ & [179] \\
\hline & n.d. & $154.5 \mathrm{mg} / \mathrm{g}_{\text {dry weight }}$ & Lignin from rice bran & R. oryzae & [178] \\
\hline & $13.2 \mu \mathrm{g} / \mathrm{mL}$ & $160 \mu \mathrm{g} / \mathrm{mL}$ & & A. niger IBS-103ZA & [180] \\
\hline Orsellinic acid (16) & $0 \mathrm{mg} / \mathrm{g}$ & $33 \mathrm{mg} / \mathrm{g}$ & $\begin{array}{l}\text { Dextrose from Sabouraud } \\
\text { medium }\end{array}$ & P. polonicum $\mathrm{C} 3$ & [174] \\
\hline Protocatechuic acid (10) & $8.7 \pm 1.2 \mathrm{mg} / \mathrm{g}_{\text {dry weight }}$ & $13.6 \mathrm{mg} / \mathrm{g}_{\text {dry weight }}$ & Lignin from rice bran & R. oryzae & [178] \\
\hline \multirow[t]{3}{*}{ Vanillic acid (4) } & $0 \mathrm{mg} / \mathrm{L}$ & $250 \mathrm{mg} / \mathrm{L}$ & Ferulic acid, $4 \mathrm{mmol} / \mathrm{L}$ & S. thermophile & [173] \\
\hline & $0 \mathrm{mg} / \mathrm{L}$ & $365 \mathrm{mg} / \mathrm{L}(36.5 \%)$ & Ferulic acid, $1 \mathrm{~g} / \mathrm{L}$ & H. elognata & [171] \\
\hline & $0 \%$ & $57.3 \%$ & Ferulic acid & P. lactis SAMS-2001 & [170] \\
\hline \multirow[t]{2}{*}{ Syringic acid (11) } & $2.6 \pm 0.6 \mathrm{mg} / \mathrm{g}_{\text {dry weight }}$ & $12.7 \mathrm{mg} / \mathrm{g}_{\text {dry weight }}$ & $\begin{array}{l}\text { Lignin from rice bran } \\
\text { Sinapic acid }(5 \mathrm{mM})\end{array}$ & R. oryzae & [178] \\
\hline & $0 \mathrm{mg} / \mathrm{L}$ & $85 \mathrm{mg} / \mathrm{L}$ & $\begin{array}{l}\text { solution in minimal } \\
\text { medium }\end{array}$ & P. variotii & [167] \\
\hline$p$-Coumaric acid (26) & $71.8 \mu \mathrm{g} / \mathrm{mL}$ & $146 \mu \mathrm{g} / \mathrm{mL}$ & Palm oil mill effluent * & A. niger IBS-103ZA & [180] \\
\hline \multirow[t]{2}{*}{ Caffeic acid (31) } & $1.6 \pm 0.2 \mathrm{mg} / \mathrm{g}_{\text {dry weight }}$ & $28.7 \mathrm{mg} / \mathrm{g}_{\text {dry weight }}$ & Lignin from rice bran & R. oryzae & [178] \\
\hline & $286 \mu \mathrm{g} / \mathrm{mL}$ & $340 \mu \mathrm{g} / \mathrm{mL}$ & Palm oil mill effluent * & A. niger IBS-103ZA & [180] \\
\hline \multirow[t]{3}{*}{ Ferulic acid (27) } & $159 \mu \mathrm{g} / \mathrm{mL}$ & $225 \mu \mathrm{g} / \mathrm{mL}$ & Palm oil mill effluent * & A. niger IBS-103ZA & [180] \\
\hline & $10.56 \pm 2.46$ & $69.98 \pm 13.75 \mu \mathrm{g} / \mathrm{g}$ & $\begin{array}{l}\text { Hemicelluloses from } \\
\text { kidney bean extract }\end{array}$ & B. subtilis & [177] \\
\hline & $0 \%$ & $\begin{array}{l}85 \% \text { of alcaline extracted } \\
\text { compounds }\end{array}$ & Pectin in sugar beet pulp & P. chrysogenum 31B & {$[181]$} \\
\hline Hypogallic acid (9) & $0 \mathrm{mM}$ & $2.9 \mathrm{mM}$ (50.4\% yield) & $m$-Hydroxybenzoate & P. testosteroni & [182] \\
\hline
\end{tabular}

${ }^{*}$ The substrate is not designated. 


\subsection{Biosynthesis of Phenolic Acids from Organic Wastes Using Non-Modified Microorganisms}

Microbial fermentation of waste is the most important processes because it allows for the reduction of the amount of organic waste and for the production of valuable bioactive compounds [177]. Microbial fermentation of waste can be carried out in a solid or liquid state, depending on the free floating water amount. Only the solid state fermentation can be performed by the limited quantity of microorganisms [183]. The substrate, desired products, and required enzymes determine the ability to employ the particular microorganism in each process. Other factors that influence the fermentation process are raw material; fermentation type (solid or liquid state); as well as temperature, dissolved oxygen concentration, $\mathrm{pH}$, and microorganisms employed for the fermentation [177]. For this reason, the optimal fermentation conditions can lead to higher yields of phenolic acids, whereas inappropriate parameters (such as temperature) can even cause the death of the applied microorganisms [184]. In individual cases, other parameters can also be important. For example, sucrose concentration, $\mathrm{MnSO}_{4}$ concentration, and incubation temperature were the main parameters that significantly influenced phenolic acid production in palm oil mill effluent fermentation by A. niger IBS-103ZA [180]. The phenolic acids released during microbial fermentation can also have an inhibitory effect on the growth of microorganisms due to the increased quantity of hydrogen protons, which acidifies the cytoplasm of the microorganisms and inhibits metabolic functions [185].

Agricultural waste usually contains mostly lignin, cellulose, or hemicellulose, but also can contain gallotanins, tannic acids, various phenolic glucosides, and pectines. Depending on the raw material, researchers employ different microorganisms for the fermentation process. Some examples of these processes are presented in Table 5. Bacillus sp., Rhodococcus jostii, Pandoreae sp., and white-rot fungi can catabolise the lignin-containing waste and produce phenolic acids as intermediate compounds [186-188]. Therefore, some microorganisms such as Acetoanaerobium sp. WJDL-Y2 can produce ferulic and syringic acids from lignin as the final metabolites [189]. Ferulic acid from pectine of sugar beet pulp can be released by Penicillium chrysogenum [181]. It was determined that the produced ferulic acid esterase from P. chrysogenum can even hydrolyse hydroxybenzoic acid methyl esters [181]. Similarly, Rhizopus oryzae fungus was employed for the fermentation of rice bran, after which the greatest change in concentration was observed for ferulic acid (from $33 \mathrm{mg} / \mathrm{g}$ to $765 \mathrm{mg} / \mathrm{g}$ ) [178]. Food-grade fungus Lentinus edodes CY-35 produces high levels of extracellular $\beta$-glucosidase, which is the major enzyme responsible for hydrolysing phenolic glucosides from cranberry pomace for the production of free gallic, $p$-hydroxybenzoic, and p-coumaric acids [190]. Only lactic acid bacteria such as Lactobacillus arizononas R13, Lactobacillus plantarum FST1.7, Lactobacillus reuteri R2, and Weisella cibaria PS2 can produce vanillic acid (up to $4.3 \mathrm{mg} / \mathrm{L}$ ), $p$-hydroxybenzoic acid (up to $1.5 \mathrm{mg} / \mathrm{L}$ ), $\rho$-coumaric acid (up to $14.0 \mathrm{mg} / \mathrm{L}$ ), and salicylic acid (up to $9.9 \mathrm{mg} / \mathrm{L}$ ) from the glucose using de Man, Rogosa and Sharpe (MRS) broth [191]. Lactic acid bacteria can also release $p$-coumaric acid, as well as caffeic and salycilic acids from grass [192]. However, natural fermentation (or composting) can also have a negative influence, causing the reduction in the concentration of phenolic acids (caffeic, vanillic, gallic), as reported in olive cakes [149]. 


\subsection{Food and Beverage Enrichment with Phenolic Acids}

Microbial fermentation is widely applied in the food industry. Alongside main fermentation products such as ethanol or lactic acid, it can generate various secondary metabolites, including phenolic acids. For example, after wine fermentation, the total amount of phenolic acids increases 1.5-2.0-fold because of increased concentrations of hydroxybenzoic acids (gallic, protocatechuic, vanillic, $p$-hydroxybenzoic, gentisic acids) [193]. Wheat bread doughs are enriched with phenolic acids, while the quality and properties of the doughs depend on the phenolic acid composition and amount [194]. L. plantarum strains LB126, 29DAN, and 98A are able to enrich the doughs in ferulic acid up to $400 \mu \mathrm{g} / \mathrm{g}$ DW, whereas the concentration of other phenolic acids such as caffeic, sinapic, p-hydroxybenzoic, and gallic acids is much lower (0.4-23.0 $\mu \mathrm{g} / \mathrm{g}$ DW) [195]. R. oryzae RCK2012 has been used in wheat fermentation, enabling enrichment of final substance with $p$-hydroxybenzoic and vanillic acids [196].

\subsection{Engineered Microorganisms for Phenolic Acid Production}

Engineered microorganisms can be an alternative for the production of phenolic acids, which can be toxic compounds for microorganisms in low or high concentrations [197,198]. For this reason, the processes for the production of phenolic acids in high yields can be developed by the overexpression of efflux proteins or the use of microorganisms that are naturally resistant or show a high tolerance to the phenolic compounds and to the whole biochemical reactions that take place in organisms [198-200]. Some bacteria (Esherichia coli, Pseudomonas putida, Corynebacterium glutamicum) and yeast (Saccharomyces cerevisiae) can be genetically modified for the production of different phenolic acids. Both bacteria and yeasts are relatively economically feasible, fast-growing systems that can be cultured in bioreactors with high cell density [200].

\subsubsection{Shikimate Pathway in Engineered Microorganisms}

The microbial biosynthesis of phenolic acids is rather similar to the reactions occurring in the plants. Engineered microorganisms are mostly developed to produce phenolic acids via the shikimate pathway (Figure 2), which is the primary biosynthetic route for synthesising aromatic amino acids and their derivatives [201,202]. Microorganisms can be engineered to utilise different carbon sources, renewable sugars, glucose, xylose, or glycerol or precursors for production of these compounds [198,203]. The precursors can be other phenolic acids or amino acids [204,205]. Therefore, the product yields in microbial synthesis are ultimately limited by the mechanism utilised for glucose transport [206]. The condensation of glycolytic intermediate phosphoenolpyruvate (PEP) and pentose phosphate pathway intermediate erythrose-4-phosphate (E4P) allows for the generation of shikimate, which is converted to chorismate. Chorismate is the major intermediate in this shikimate pathway. All transformations of chorismate can be performed with different native or engineered enzymes obtained from bacteria, yeast, fungi, or plants. 


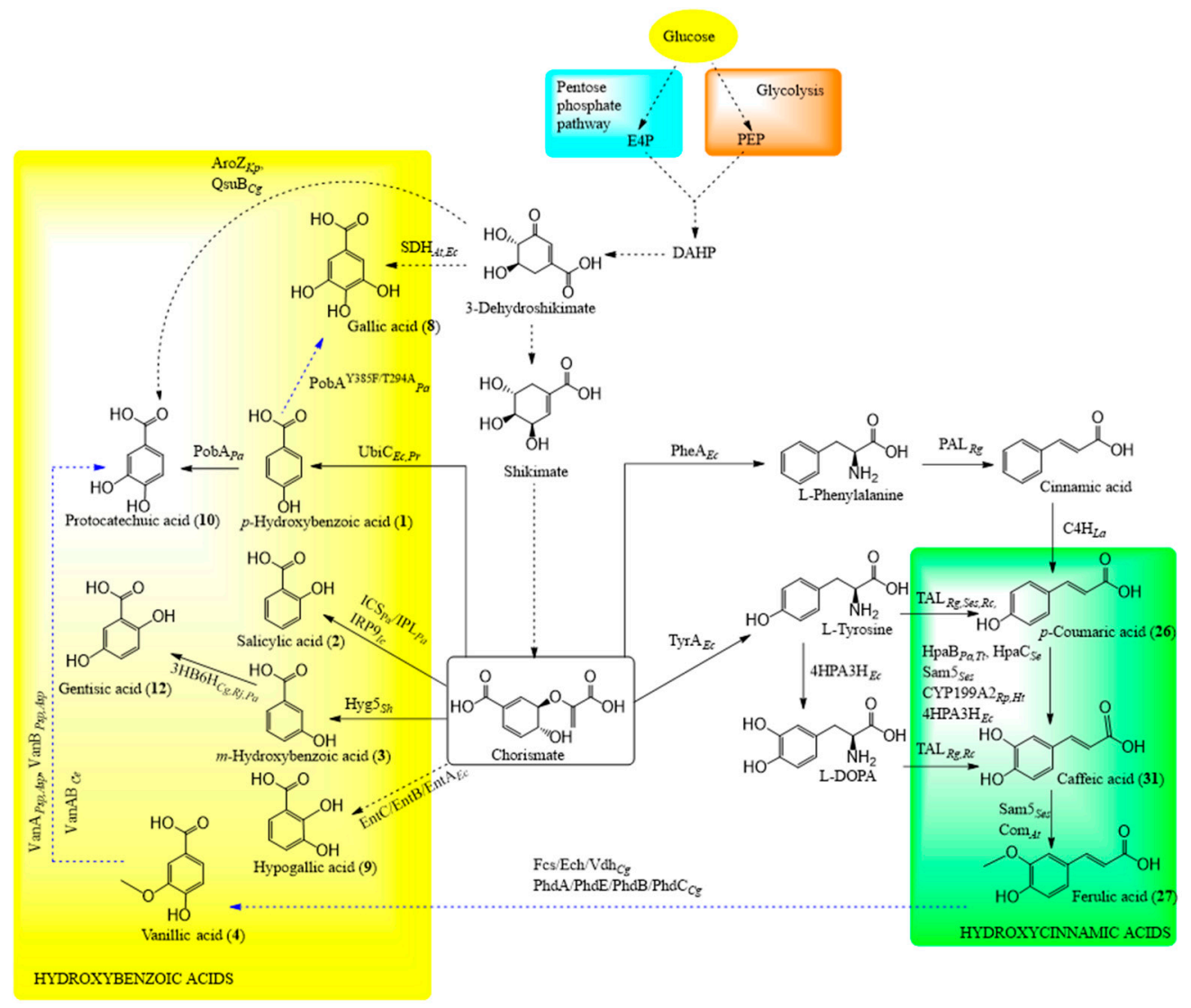

Figure 2. General pathways for the biosynthesis of phenolic acids by the engineered microorganisms. Solid arrows indicate the direct conversion, and the dotted arrows indicate the conversion through two or more reactions. Black arrows show phenolic acid production from glucose while blue arrows indicate their production from precursors. Abbreviations: aroZ, dehydroshikimate dehydratase; $\mathrm{C} 3 \mathrm{H}$, 4-coumarate 3-hydroxylase; $\mathrm{C} 4 \mathrm{H}$, trans-cinnamic acid 4-hydroxylase; COMT5, caffeic acid 3-O-methyltransferase; CYP199A2, cytochrome p450 CYP199A2; 3,5-DHS, 3,5-dehydroshikimate; 3-DHS, 3-dehydroshikimate; E4P, erythrose-4-phosphate; Ech, enoyl-coenzyme A hydratase/aldolase; EntA, 2,3-dihydro-2,3-dihydroxybenzoic acid dehydrogenase; EntB, isochorismatase; EntC, isochorismate synthase; Fcs, feruloyl-CoA synthase; HpaB and $\mathrm{HpaC}$, 4-hydroxyphenylacetate 3-monooxygenase oxygenase components; 4HPA3H, 4-hydroxyphenylacetate 3-hydroxylase; 3-HBA, m-hydroxybenzoic acid; 4-HBA, 4-hydroxybenzoic acid; 3HB6H, 3-hydroxybenzoate 6-hydroxylase; Hyg5 encodes chorismatase/3-hydroxybenzoate synthase; L-DOPA, L-3,4-dihydroxyphenylalanine; ICS, isochorismate synthase; IPL, isochorismate pyruvate lyase; IRP9, salicylate synthase; PAL, phenylalanine ammonia-lyase; PEP, phosphoenolpyruvate; pheA, chorismate mutase/prephenate dehydratase; PobA, p-hydroxybenzoate hydroxylase; PhdA, acyl-CoA ligase; PhdB, 3-hydroxyacyl-CoA dehydrogenase; PhdC, 3-oxoacyl-CoA ketohydrolase; PhdE, enoyl-CoA hydratase; QsuB, 3-dehydroshikimate dehydratase; Sam5, 4-coumarate 3-hydroxylase; SDH, shikimate dehydrogenase; TAL, tyrosine ammonia lyase; tyrA, prephenate; UbiC, chorismate lyaze; VanA and VanB ( or VanAB), the terminal oxygenase (VanA) and the reductase (VanB) are subunits of the vanillate-O-demethylase; Vdh, vanillin dehydrogenase. The enzymes/genes sources: Asp, Acinetobacter spp; At, Arabidopsis thaliana; Ce, Corynebacterium efficiens; Cg, Corynebacterium glutamicum, Ec, Esherichia coli; Ht, Helianthus tuberosus; Kp, Klebsiella pneumoniae; La, Lycoris aurea; Pa, Pseudomonas aeruginosa; Pr, Providencia rustigianii; Psp, Pseudomonas spp; Rc, Rhodobacter capsulatus; Rg, Rhodotorula glutinis; Rj, Rhodococcus jostii; Rp, Rhodopseudomonas palustris; Se, Salmonella enterica; Ses, Saccharothrix espanaensis; Sh, Streptomyces hygroscopicus; Tt, Thermus thermophilus; Ye, Yersinia enterocolitica. 


\subsubsection{Biosynthesis of Hydroxycinnamic Acids}

p-Coumaric acid can be obtained from cinnamic acid [207] or tyrosine [204] using glucose as a carbon source [208]. Cinnamic acid is usually produced from phenylalanine. L-Phenylalanine or L-tyrosine are formed from chorismate or directly added into the media as precursors. The extension of this pathway leads to the production of caffeic acid and ferulic acid [209]. The conversion of coumaric acid to caffeic acid can be mediated by 4-hydroxyphenylacetate 3-hydroxylase (4hp3h), 4-coumarate 3-hydroxylase encoded in sam5, 4-hydroxyphenylacetate 3-monooxygenase (hpaC and $h p a B)$, or cytochrome P450 [210-214]. Therefore, for the latter, it is difficult to express in the bacterial systems and requires the co-expression of redox partners-the putida redoxin reductase gene ( $p d R)$ and the palustris redoxin gene ( $p u x)$ from Rhodopseudomonas palustris in the host organism [210,215]. Caffeic acid is also produced from tyrosine through 3,4-dihidroxyphenylalanine (L-DOPA) with mediation by the enzymes 4-hydroxyphenylacetate 3-hydroxylase $(4 \mathrm{HPA} 3 \mathrm{H})$ and tyrosine ammonia lyase (TAL) [211]. Caffeic acid 3-O-methyltransferase mediates the methylation of caffeic acid to ferulic acid [216]. Sinapic acid is produced through the oxidation of sinapaldehyde by E. coli after expressing gene ref1, which encodes a sinapaldehyde dehydrogenase required for sinapic acid and sinapate ester biosynthesis [217]. The latter modified bacterium was also able to convert coniferaldehyde to ferulic acid as well.

\subsubsection{Biosynthesis of Hydroxybenzoic Acids}

Chorismate is converted directly to the $o_{-}, m_{-}$, and $p$-hydroxybenzoic acids [218]. Gentisic and protocatechuic acids are obtained from the $m$ - and $p$-hydroxybenzoic acids, respectively, after hydroxylation. Gallic acid is synthesised from 3-dehydroshikimate with the mediation of shikimate dehydrogenase or from $p$-hydroxybenzoic acid with mediation by mutant hydroxylase [219,220]. Hypogallic acid can be produced in E. coli when chorismate is first converted to isochorismate, then to 2,3-dihydroxy-2,3-dihydrobenzoic acid (2,3-dihydro-2,3-DHBA), and finally to this phenolic acid by the mediation of isochorismate synthase, isochorismatase, and 2,3-dihydro-2,3-DHBA dehydrogenase, respectively [221]. Protocatechuic acid is synthesised from ferulic acid through non- $\beta$-oxidative or $\beta$-oxidative CoA-dependent pathways, where the last step is the biotransformation of vanillic acid mediated by vanillate O-demethylase [222,223]. Vanillic acid is synthesised from ferulic after disruption of vanA and vanB genes from Pseudomonas fluorescens and P. putida using $p$-coumaric acid or ferulic acid extracted from corn bran [205,224]. Syringic acid is produced during oxidation of syringaldehyde by the engineered E. coli, after insertion of $\operatorname{des} V$ and $\operatorname{lig} V$ genes [225].

The secondary metabolites of fungi (6-methyl salicylic (21), orsellinic and $\alpha$-resorcylic (13) acids) and olivetolic acid can be produced as the final compounds from coenzymes (malonyl-CoA, acethyl-CoA, propionyl-CoA, hexanoyl-CoA) of acetyl-malonate or propionyl pathways, after expression of polyketide synthase genes in engineered microorganisms. $\alpha$-Resorcylic acid is biosynthesised from maltose in Aspergillus oryzae RIB40 after overexpression of tetraketide alkyl-resorcinol/resorcylic acid synthase csy $A$ gene under the control of the promoter amyB in $A$. oryzae [226]. The expression of phosphopantetheinyl transferase gene $n p g A$ of Aspergillus nidulans and 6-methylsalicylic acid synthase (6-MSAS) gene atX from Aspergillus terrus in Pichia pastoris resulted in the production of 6-methylsalicylic acid from methanol [227]. Later, the overexpression of the hrk1 gene, which is responsible for the tolerance and acetyl-CoA synthetase ScAcs1 from engineered P. pastoris in K. phaffii, resulted in the production of 6-methyl salicylic acid from acetate [228]. 6-Methylsalicylic acid synthase, which consists of a few domains (such as ketoacylsynthase, acyltransferase, thioester hydrolase, ketoreductase, and acyl carrier protein), is activated by phosphopantetheinylation, and then it is able to catalyse the synthesis of 6-methyl salicylic acid from one acetyl-CoA and three malonyl-CoA under consumption of one dihydronicotinamide-adenine dinucleotide phosphate (NADPH) via oxidation and decarboxylation reaction $[229,230]$. High titer of 6-methyl salicylic acid $(440.3 \mathrm{mg} / \mathrm{L})$ was achieved by the production of engineered E. coli from glycerol in fed-batch fermentation after overexpression of 6-methyl salicylic acid synthase gene from Penicillium griseofulvum and the accBCD1 gene from 
C. glutamicum and knocking down the pabA gene [231]. Orsellinic acid was also produced after the expression of the BY1 gene from basidiomycetes in A. niger with the mediation of non-reducing polyketide synthases $p k s 1$ and $p k s 2$ [232]. For the production of olivetolic acid in engineered E. coli, the olivetolic acid synthase (ols) and cyclase (olc) genes from C. sativa were inserted for the synthesis of this compound from hexanoyl-CoA and malonyl-CoA [233]. For the biosynthesis of hexanoyl-CoA, the module of the $\beta$-oxidation reversal was also engineered. After optimisation of temperature, inducer concentrations of isopropyl $\beta$-d-1-thiogalactopyranoside (IPTG) or cumate, and working volume, the engineered strain produced $80 \mathrm{mg} / \mathrm{L}$ from glycerol suplemented with hexanoate in the first $24 \mathrm{~h}$ [233].

Some examples from literature $[199,204-210,214,217,218,221,224-228,231,233-244]$ of the highest production of phenolic acids biosynthesised by the engineered microorganisms are presented in Supplementary Materials Table S1. However, there are no data on the production of other phenolic acids, such as isovanillic, $o$-vanillic (7), and isoferulic acids and isomers of $p$-coumaric, 6-methyl salicylic, and $\alpha$-resorcyllic acids, by the engineered microorganisms.

\section{Techniques for Extraction and Analysis of Phenolic Acids}

The extraction of phenolic acids for large scale production is a complex process. An extraction scheme typically involves four stages: pre-treatment (or preparation) of material, extraction, purification, and analysis of the obtained extracts.

\subsection{Preparation of Material}

Before the extraction of phenolic compounds from either fresh or dried raw biomass, a pre-treatment step is typically performed. The biomass is usually milled or ground to reduce the size and increase effective surface area. For efficient recovery of phenolic acids, we can remove non-polar compounds such as lipids, chlorophyll, and steroids can from samples before the extraction. Defatting is achieved with the use of non-polar solvents such as hexane, supercritical carbon dioxide, and others.

\subsection{Extraction}

The defatted plant feedstocks are then ready for the extraction of phenolic acids with different polar or partially polar solvents such as methanol, ethanol, water, acetone, or ethyl acetate. For extraction of bound or conjugated phenolic acids—enzymatic or chemical—by an acid or base, we can perform hydrolysis. Conjugated forms of phenolic acids, for example, are more likely to be released by alkaline hydrolysis rather than hydrolysis in acidic conditions [245]. Frequently, ester or ether forms of bound phenolic acids are extracted in higher amounts with alkaline $(\mathrm{pH} \geq 7)$ or acidified $(2 \leq \mathrm{pH}<7)$ solvents, respectively [246]. For the prevention of caffeic acid degradation under alkaline conditions, we can use citric acid and ethylenediaminetetraacetic acid (EDTA) [247]. Enzyme-assisted extraction with various natural or recombinant enzymes, such as esterases, pectinases, tannases, or xylanases, can also enable the release of phenolic acids from plants [248-255]. This method alone is used to produce phenolic acids from waste instead of the use of solid (or liquid) state fermentation with microorganisms.

Several different extraction techniques have been suggested for recovery of phenolic acids from various matrices. Depending on whether the solvent is required, we can divide these techniques into solvent-less extraction techniques and solvent-based techniques. Solvent-less extractions use conventional presses and modern techniques such as microwave hydrodiffusion and gravity (MHG), pulsed electric fields (PEF), instant controlled pressure drop (DIC), and others [256].

Solvent-based techniques can be further categorized into solid-liquid extraction (SLE) and liquid-liquid extraction (LLE). There are a few commonly used SLE techniques. Maceration and percolation are the simplest forms of SLE that can be performed with cold or hot solvents. Pressurised liquid extraction (PLE) combines high temperature and pressure with liquid solvents to quickly and efficiently extract the analytes from the solid matrix [257]. In ultrasound-assisted extraction (UAE), cavitation effects, which occur during ultrasonic irradiation, lead to enhanced extraction of targeted analytes via a series of mechanisms including fragmentation, erosion, capillarity, detexturation, and 
sonoporation [258]. The supercritical fluid extraction (SFE) is performed with liquid carbon dioxide with or without the addition of co-solvents at high pressure. Other non-conventional extraction techniques that have been suggested include microwave-assisted extraction (MAE), high-voltage electrical discharges, and high-hydrostatic pressure. Two or more extraction techniques can be combined for the extraction of phenolic acids since each method has its advantages and disadvantages. For example, maceration and percolation do not require high investment or operation costs but require more time [259] and solvents when compared with PLE. Moreover, increased yields of recovered phenolic acids have been typically reported with non-conventional techniques such as MAE, UAE, and PLE. Nevertheless, for any extraction method, the recovery of phenolic acids significantly depends on the type of solvent, temperature, time of extraction, solid to solvent ratio, and the stability of phenolic acids under the applied extraction conditions [259-262]. For example, in MAE, the phenolic acids containing fewer substituents in the aromatic ring or methoxy instead of hydroxyl group exhibit higher stability than hydroxyl group-rich compounds [263]. On the other hand, in UAE, protocatechuic, $p$-hydroxybenzoic, vanillic, $p$-coumaric, and ferulic acids are stable up to $65{ }^{\circ} \mathrm{C}$, while sinapic and caffeic acids degrade under ultrasound treatment [264].

\subsection{Separation}

Typically, the obtained crude extracts will contain a mixture of different phenolic acids as well as other compounds (e.g., flavonoids, pigments) [101,116,265]. If necessary, the crude extracts can be further fractionated or purified by means of preparative chromatographic techniques (i.e., preparative high pressure liquid chromatography (HPLC), thin-layer, flash, or counter-current chromatography (CCC)) or other techniques such as liquid-liquid extraction (LLE) and solid phase (SPE) extraction [266]. In these cases, compounds of interest can be separated according to their polarity, affinity to the stationary phase, or their solubility in one of the two immiscible solvents. Typical solvents in LLE include water and a nonpolar organic solvent (e.g., diethyl ether) or the use of ionic liquids $[267,268]$. In SPE, depending on the physicochemical properties of analytes, elution of the desired analytes of interest or undesired impurities in the sample from the stationary phase can be achieved with various solvents. In matrix solid-phase dispersion, a variation of SPE samples can be mixed with solid sorbents and solvents for simultaneous preparation, extraction, and fractionation of solid, semi-solid, or highly viscous biological samples. For this method, the selection of the most appropriate elution agent and the volume of elution media are necessary to be determined in order to achieve a high recovery of phenolic acids [269].

\subsection{Analysis of Phenolic Acids}

Various chromatographic techniques can perform qualitative and quantitative analysis of the extracted compounds including phenolic acids. For phenolic acid analysis, the method of choice are HPLC systems, which can be coupled to detectors such as ultraviolet light, diode array, fluorescence, or mass spectrometer (MS). Samples can also be analysed, typically after derivatisation, by gas chromatography (GC) systems coupled to flame ionisation, electron capture, or mass spectrometry detection. Other suggested techniques for the analysis of phenolic acids include CCC or capillary electrophoresis (CE) and nuclear magnetic resonance spectroscopy (NMR). CCC is advantageous due to its low cost, low solvent consumption, low risk of sample denaturation, minimised tailing of the chromatograms, and lack of irreversible absorption or loss of the substances injected into the system [270]. On the other hand, CE can be chosen due to the minimal sample volume required, short analysis time, and high separation efficiency [271]. NMR, on the other hand, offers a unique advantage over the above-mentioned techniques for structural characterisation of purified complex or novel natural products. Besides the analysis of isolated compounds, NMR-based metabolomics have gained popularity over the last two decades with, however, less sensitivity as compared to LC- or GC-based metabolomics [272]. 


\subsection{Alternative Methods for Quantification of Phenolic Acids: Biosensors}

The biosensor approach is an alternative to the analytical methods described above for the quantification of phenolic acids. Typically, bio-sensors consist of three components: recognition element (bioselective membrane); physical transducer; and electronic system for signal amplification, recording, and data representation [273]. Biosensors can be classified according to the type of transducer, or the nature of the biological entity of the recognition element [273]. Transducer-type biosensors can be electrochemical (ampiometric and potentiometric), electrical (conductometric and ion-sensitive), optical, piezoelectric (mass detection methods; acustic and microcantilever), and thermal detection [273]. The biological entity can be an enzyme, nucleic acid, antibody, hormone, lectine, cell structure, or tissue, but for phenolic acids, bio-sensors enzymes, and cells are applied. These components interact specifically with target compounds, and as a result, the occurred biochemical reaction is transformed into measurable signal through transducer.

Biosensors can find important applications for phenolic acid determination in the food and nutraceutical industry, or for environmental screening. The major types of biosensors of phenolic acid monitoring are discussed below.

\subsubsection{Enzyme-Based Biosensors}

Enzyme-based biosensors are typically constructed using highly active extracellular enzymes from fungi or bacteria, which are immobilised on the surface of the electrode (e.g., graphite electrode). Immobilisation of enzymes on the electrode surface is one of the critical steps that determine the effectiveness of the enzymatic biosensor by preserving the specificity and native structure of the enzyme [274]. Different enzymes such as laccases, tyrosinases, laccase-tyrosinases, or peroxidases are applied for the determination of phenolic acids or polyphenols in beer, wine, honey, or extracts [275-278]. Enzyme-based biosensors are amperometric forms and can be sensitive not only to simple molecules, such as caffeic acid, but to more complex structures. For example, the use of laccase from white-rot fungi Cerrena unicolor allowed the construction of a biosensor for caffeic acid monitoring in a flow-injection system, which can also be applied to detect more complex compounds, with three or more aromatic rings with different sensitivity [276]. Amperometric biosensors are known to have only a narrow linear range for the specific compounds in the $\mu \mathrm{mol} / \mathrm{L}$ region.

\subsubsection{Transcription Factor-Based Biosensors}

Transcription factor (TF)-based gene expression systems can be applied as genetically encoded biosensors for the detection and monitoring of various metabolites [279,280], including phenolic acids. TF-based biosensors are composed of a transcription factor-based inducible gene expression system, which regulate the correct level of gene expression in the engineered microorganism that responds to the specific compounds such as one or more phenolic acids. TF-based biosensor structure consists of sensor-promoter-reporter genes. The use of a fluorescent reporter gene enables the monitoring of the concentration of the analyte by fluorescence output, proportional to the concentration, easily and rapidly. Sensor-reporter systems are used for real-time monitoring and high-throughput screening of phenolic acids, whereas sensor-actuators are used for adaptive laboratory evolution and dynamic pathway control [281].

For many phenolic acids, TF-based biosensors have been developed, and they are listed in Table 4. The major application of these biosensors is for sensing of compounds produced in lignin valorisation. The transcription factors of LysR, MarR, PadR, AraC/XylS, and IclR families are applied in repressor- and activator-type biosensors using different host organisms such as E. coli, P. putida, Pseudomonas fluosrescens, S. cerevisiae, and C. glutamicum. The dynamic ranges of other biosensors reach from 1- to over 200-fold (Table 6) when the concentration of analyte does not exceed $20 \mathrm{mM}$. TF-based biosensors specific to salicylic acid and $p$-coumaric acid have been shown to possess the highest dynamic range of more than 100-fold [282-284]. The repressor-type TF-based biosensors have 
more flexibility in changing the TF binding site position in the reporter promoter, which is impossible for the activator-type TF-based biosensors [279]. Therefore, activation-type biosensors are easier and more convenient to use because the signal is directly proportional to the concentration of the activator. The specificity of constructed biosensors depends on the purpose of the biosensor, and some of them are designed to sense structurally similar compounds $[285,286]$.

Table 6. Transcription factor-based microbial biosensors for phenolic acids.

\begin{tabular}{|c|c|c|c|c|}
\hline $\begin{array}{l}\text { Target Molecule of } \\
\text { Phenolic Acid }\end{array}$ & Sensing Element ${ }^{a}$ & Output Element $^{b}$ & $\begin{array}{c}\text { Dynamic Range } \\
\text { (At the } \\
\text { Concentration of } \\
\text { Analyte) }\end{array}$ & Reference \\
\hline \multirow{5}{*}{ Protocatechuic acid (10) } & PcaU & Engineered $\mathrm{P}_{p c a U}$ & $14(20 \mathrm{mM})$ & [287] \\
\hline & $\mathrm{PcaU}^{\mathrm{AM}}$ & Engineered $\mathrm{P}_{p c a U}, \mathrm{P}_{3 B 5 B}$ & $1.5 ; 1.8(1 \mathrm{mM})$ & [285] \\
\hline & PcaV & Engineered $\mathrm{P}_{P v}$ & $3(1 \mathrm{mM})$ & [288] \\
\hline & PcaU & Engineered $\mathrm{P}_{p c a U}$ & $\approx 12(0.003 \mathrm{mM})$ & [289] \\
\hline & Engineered PobR & $\mathrm{P}_{p o b R}$ & $64(10 \mathrm{mM})$ & [290] \\
\hline \multirow[t]{7}{*}{ Vanillic acid (4) } & VanR & $\mathrm{P}_{T E F 1}$ & $\approx 8(4 \mathrm{mM})$ & [279] \\
\hline & EmrR & $\mathrm{P}_{E m r R}$ & $1(50 \mu \mathrm{M})$ & [291] \\
\hline & & Engineered $\mathrm{P}_{E m r R}$, & $9.5(5 \mathrm{mM})$ & \\
\hline & Engineered EmrR & $\mathrm{P}_{\text {vtac }}$ & $6.8(5 \mathrm{mM})$ & [292] \\
\hline & & $\mathrm{P}_{\text {vtrc }}$ and $\mathrm{P}_{\text {vtic }}$ & $2.1(5 \mathrm{mM})$ & \\
\hline & VanR-VanO & Engineered $\mathrm{P}_{\operatorname{Van} A B}$ & $14(1 \mathrm{mM})$ & [293] \\
\hline & $\operatorname{VanR}_{\mathrm{am}}$ & $\mathrm{P}_{\text {VanCC }}$ & $2.3(100 \mu \mathrm{M})$ & [285] \\
\hline \multirow[t]{4}{*}{ p-Hydroxybenzoic acid (1) } & EmrR & $\mathrm{P}_{\text {EmrR }}$ & $0.5(1 \mathrm{mM})$ & [291] \\
\hline & PobR variant & $\mathrm{P}_{p o b}$ & $64(1 \mathrm{mM})$ & [290] \\
\hline & PobR variant & $\mathrm{P}_{p o b}$ & $\approx 12(30 \mathrm{mM})$ & [294] \\
\hline & PcaV & Engineered $\mathrm{P}_{\mathrm{Pv}}$ & $3.6(1 \mathrm{mM})$ & [288] \\
\hline m-Hydroxybenzoic acid (3) & PcaV & Engineered $\mathrm{P}_{\mathrm{Pv}}$ & $2.8(1 \mathrm{mM})$ & [288] \\
\hline \multirow[t]{4}{*}{ Salicylic acid (2) } & AraC-TAL & $\mathrm{P}_{B A D}$ & $218(5 \mathrm{mM})$ & [283] \\
\hline & NahR ${ }^{A M}$ & $\mathrm{P}_{\text {salTCC }}$ & $2.1(100 \mu \mathrm{M})$ & [285] \\
\hline & Engineered AraC & $\mathrm{P}_{B A D}$ & $\approx 200(5 \mathrm{mM})$ & [284] \\
\hline & SalR & $\mathrm{P}_{\text {sal }}$ & $10 \mathrm{uM}$ & [295] \\
\hline 4-Methylsalicylic acid (20) & NahR, NahF-R & $\mathrm{P}_{J 23114}$ & $\approx 2(1 \mathrm{mM})$ & [296] \\
\hline \multirow{2}{*}{ 3-Methylsalicylic acid (19) } & XylS & $\mathrm{P}_{m}$ & $\approx 2(1 \mathrm{mM})$ & [296] \\
\hline & NahF-R & $\mathrm{P}_{J 23114}$ & $\approx 2(1 \mathrm{mM})$ & [296] \\
\hline Hypogallic acid (9) & NahR, NahF-R & $\mathrm{P}_{223114}$ & $\approx 2(1 \mathrm{mM})$ & [296] \\
\hline \multirow[t]{4}{*}{$p$-Coumaric acid (26) } & EmrR & Engineered $\mathrm{P}_{\text {EmrR }}: P_{\text {vtac }}, P_{\text {vtrc }}$ & 10.4 and $8.5(1 \mathrm{mM})$ & [292] \\
\hline & AraC-TAL & $\mathrm{P}_{B A D}$ & $2.3(5 \mathrm{mM})$ & [283] \\
\hline & FerC & Engineered $\mathrm{P}_{L C}$ & $25(1 \mathrm{mM})$ & [286] \\
\hline & PadR & $\mathrm{P}_{\text {padC }}$ & $\approx 130(2 \mathrm{mM})$ & [282] \\
\hline Ferulic acid (27) & FerC & Engineered $\mathrm{P}_{L C}$ & $26.2(1 \mathrm{mM})$ & [286] \\
\hline Caffeic acid (31) & FerC & Engineered $\mathrm{P}_{L C}$ & $11.2(1 \mathrm{mM})$ & [286] \\
\hline Sinapic acid (30) & FerC & Engineered $\mathrm{P}_{L C}$ & $15.4(1 \mathrm{mM})$ & [286] \\
\hline Umbellic acid (32) & FerC & Engineered $P_{L C}$ & $9.6(1 \mathrm{mM})$ & [286] \\
\hline 5-Hydroxyferulic acid (28) & FerC & Engineered $\mathrm{P}_{L C}$ & $14.8(1 \mathrm{mM})$ & [286] \\
\hline Isoferullic acid (29) & FerC & Engineered $P_{L C}$ & $33.5(1 \mathrm{mM})$ & [286] \\
\hline
\end{tabular}

\section{Future Perspectives and Limitations of Phenolic acid Production}

The inhibition effect of different compounds and the rate-limiting steps reduce the yield of targeted compounds. For example, for caffeic acid production from kraft pulp hydrolysate by E. coli YD01, furfural or syringic acid acted as inhibitors and reduced caffeic acid production by $20 \%$ without, however, reducing the cell growth at high concentrations [297]. The engineered E. coli strain, which converts $p$-coumaric acid to caffeic acid in the presence of flavin adenine dinucleotide (FAD) and nicotinamide adenine dinucleotide hydride (NADH), accumulated L-dopa and $p$-coumaric acid [211]. This accumulation was considered as a rate-limiting step. 


\subsection{Improved Phenolic Acid Production through Engineering Microorganisms}

Some phenolic acids such as vanilic, ferulic, caffeic, and gentisic acids are obtained in rather low concentrations by engineered microorganisms. On the other hand, others such as protocatechuic, hydroxybenzoic, $p$-coumaric, and salicylic acids can be produced in high concentrations. Nevertheless, obtained product titers are still not appropriate for the economically feasible production and application in large scale reactors. Usually, the number of differentially expressed genes and proteins involved in aromatic amino acid biosynthesis, their catabolism, and transport system are linked to the improved production of phenolic acids [298]. There are a few possible strategies for enhancing the production of desired phenolic acids in the engineered microbial cell factories, including better carbon flux control (or reduction of by-products formation), improving the product transport, increasing of the specific growth rate of the cell, or using the platforms for the utilisation of waste. The optimisation of various parameters and the use of different carbon sources could also be important for the production of phenolic acids. The optimum enzyme expression levels can be controlled by the construction of ribosome-binding sites and transposon insertion libraries [284].

\subsection{Transporters}

The intracellular and extracellular concentrations of the products or intermediates influence the obtained product concentration. The transport systems influence the intracellular concentration of phenolic acids in the engineered microorganism, and it can be related to lowering the toxicity of the products inside the cell or optimising the carbon flux. The membrane protein overexpression can lead to the creation of efflux systems where the transcription levels can result in mutations in the promoter or a slower uptake of IPTG, and it is regulated by inhibitors [299]. The different promoters influence phenolic acid production- $\mathrm{P}_{\mathrm{T} 7}$, for example, performed better than $\mathrm{P}_{\mathrm{tac}}$ and led to higher salicylic acid titer $(233.6 \pm 6.6 \mathrm{mg} / \mathrm{L})$ by E. coli [237]. The expression of transporters is affected by the carbon source [298]. Therefore, the use of heat shock promoters of $d n a K$ and $i b p A$ enabled higher $p$-coumaric acid $(119.6 \mu \mathrm{M})$ and caffeic $(13.7 \mu \mathrm{M})$ acid production in E. coli [204].

The deletion of unfavourable transporters results in the increased titers of the products. For example, the deletion of tryptophane amino-acid transporter 1 (TAT1), resulted in the increase of $p$-coumaric acid titer in 50\% in biosynthesis by S. cerevisiae [197]. The knockouts of polyamine and arginine transporters (tpo1 and alp), as well as deletion of transporters of amino acids (bap2, agp3), acetate (ady2), and galactose (gal2), gave a lower improvement in p-coumaric acid biosynthesis [197].

\subsection{Product Removal}

The extracellular concentration of the products can be lowered by employing resin-based extraction. For example, the engineered E. coli could synthesise $41 \mathrm{~g} / \mathrm{L}$ of protocatechuate under glucose-rich conditions in $48 \mathrm{~h}$ [239]. The culture medium pumping through the column filled with resin allowed for the control of the maximum concentration of protocatechuate in the media. The final concentration of this compound (eluted from resin and extracted from culture media) was $71 \mathrm{~g} / \mathrm{L}$ [239].

\subsection{Availability of Tools}

Transposon mutagenesis and codon optimisation techniques were applied for vanillic, caffeic, and $p$-hydroxybenzoic acid production in engineered microorganisms [205,214,233,236]. For successful $p$-coumaric acid biosynthesis, researchers applied high-throughput sequencing technology and gene overexpression via the CRISPR/Cas9 system [207,208]. The overexpression of endogenous yeast genes using the CRISPR/Cas9 system and optimisation of carbon distribution between glycolysis by replacing the several promoters of its genes in $S$. cerevisiae resulted in the highest production of $p$-coumaric acid (12.5 g/L) from glucose under fed-batch conditions [208].

Biosensor-guided improvements were applied for salicylic acid production [284]. In this example, the genes $\left(e n t C, p c h B, a r o L, p p s A, t k t A, a r o G^{f b r}\right.$ ) required for salicylate production were overexpressed, 
and Ara-SA sensor system was constructed in E. coli. AraC-based sensor system controlled the expression of $\beta$-galactosidase (lacZ), cleaving X-gal and generating a blue colour. After optimisation of gene expression patterns, salicylic acid production was enhanced up to $123 \%$. The transposon mutagenesis, screening, and deletion of gene encoding RNaseD ( $r n d)$ from host bacteria resulted in the additional increase of salicylate production by $27 \%$. The highest salicylate concentration $(16.5 \mathrm{mM})$ was obtained after $48 \mathrm{~h}$ induction.

\subsection{By-Products}

The carbon flux control toward the shikimate synthesis pathway can reduce the formation of undesired side-/by-products, and it results in better yields of phenolic acids [234]. The deletion of glucose metabolism repressor hexR may increase the availability of shikimate pathway precursors E4P and the necessary reducing equivalents NADPH [300]. The deletion of genes pobA, pheA, $\operatorname{trp} E$, hexR, and $\operatorname{tyr} A$ for carbon flux regulation stopped the accumulation of phenylalanine and tyrosine in E. coli or P. putida, and enhanced the concentration of $p$-hydroxybenzoic acid [237,300,301]. The deletion of hexR controlling glucokinase $(g l u)$, glyceraldehyde-3-phosphate (gap-1), and several Entner-Doudoroff pathway enzymes ( $z w f, p g l$, edd, and $e d a$ ) from P. putida KT2440 increased the flux toward pentose phosphate pathway and NADPH pool and resulted in the increased $p$-hydroxybenzoic acid production [300]. The reduction of by-product formation in $p$-coumaric acid-overproducing S. cerevisiae strain was carried out by knocking out phenylpyruvate decarboxylase $\mathrm{ARO} 10$ and pyruvate decarboxylase PDC5 and overexpressing of feedback-resistant 3-deoxy-D-arabinoheptulosonate 7-phosphate (DAHP) synthase and chorismate mutase together with overexpressing shikimate kinase enzymes from E. coli, homologous to the pentafunctional enzyme arolp and to the bifunctional chorismate synthase-flavin reductase aro $2 p$ [243].

\subsection{Enzyme Choice and Engineering}

The different types and different sources of enzymes influence the yield of the final product due to their activity. The sources of natural enzymes and their genes were compared in gentisic and caffeic acid production. The gentisate production was influenced by C. glutamicum or R. jostii genes encoding for 3-hydroxybenzoate 6-hydroxylase [237]. The endogenous 4HPA3H in E. coli was more efficient than cytochrome P450 CYP199A2 for the conversion of $p$-coumaric acid to caffeic acid [244]. However, the mutant enzymes show higher activity than natural enzymes and allow high yields of phenolic acids to be obtained. For example, the expression of engineered genes of DAHP synthase and chorismate mutase in E.coli led to the production of $p$-coumaric acid in the highest titer $(1.93 \pm 0.26 \mathrm{~g} / \mathrm{L})$ [243]. Similarly, gallic acid was produced by E. coli during conversion of $p$-hydroxybenzoic acid by $p$-hydroxybenzoate hydroxylase with Y385F and T294A mutations [240]. Thus, the overexpressed gene copy number also matters. In E. coli, up to 10 copy numbers of TAL or medium copy number vector carrying entCBA gene performed best in the production of $p$-coumaric and hypogallic acids, respectively $[209,221]$.

\subsection{Fermentation Conditions and Substrates}

Phenolic acid production is also affected by the cultivation condition (batch or chemostat cultivation) [197]; a sole or mixed carbon source [301]; and if the co-feeding of xylose, glucose, or glycerol is applied [203]. The lower purity of carbon source (crude or purified glycerol used) has a positive effect on product yields [302]. The optimisation of culture medium with yeast extract (from $1 \mathrm{~g} / \mathrm{L}$ to $5 \mathrm{~g} / \mathrm{L}$ ) resulted in the increased production of $p$-coumaric acid by engineered E. coli [242].

\subsection{Application of Other Methods}

The application of co-culture technique could enable the production of many phenolic acids from glucose. For example, the L-tyrosine-overproducing strains [303] could be applied for precursor synthesis, which could be assimilated by the modified microorganism for the production of $p$-coumaric, 
ferulic, or caffeic acids. The growth rate of bacteria can be improved by the introduction of the transcriptional regulators gntR1 (gntR1-E70K) and $\operatorname{ramA}(\mathrm{ramA}-A 52 \mathrm{~V}$ ) in the wild-type C. glutamicum background, resulting in a specific growth rate of $0.62 \mathrm{~h}^{-1}$ with an increased sugar consumption rate of around $30 \%$ in the minimal medium [304]. Therefore, better growth cannot be directly related to the increased concentration of products.

\section{Conclusions}

Phenolic acids have gained attention due to their potential health benefits, having already found applications in the agricultural, medicinal, cosmetic, nutraceutical, and food industries. From a human physiological standpoint, phenolic acids are reported to have anti-aging, anti-inflammatory, antioxidant, and anti-proliferative activities. Because of their pharmacological action and commercial value, the demand for phenolic acids is increasing. Naturally derived phenolic acids are produced as secondary metabolites by plants and engineered or natural microorganisms (bacteria, fungi, yeasts). Numerous studies, based on genetic or metabolic engineering, have focused on improving the production of phenolic acids. Additionally, metabolic engineering has enabled microbial cell factories to produce these high-value chemicals in a sustainable way. Agro-industrial wastes are also regarded as potential feedstocks for the recovery of phenolic acids. High phenolic acid yields can also be obtained in fermentation processes using natural and engineered microorganisms. The application of new genetic engineering tools enables the construction of the pathways in yeast and bacteria that produce the highest titers of phenolic acids. The optimisation of carbon flux and transcription factors, the overexpression of key genes in synthetic pathways in engineered microorganisms, and the application of the new tools of genetic engineering (CRISPR) allows us to obtain the highest titers $(>10 \mathrm{~g} / \mathrm{L})$ of phenolic acids ( $p$-hydroxybenzoic, salicylic, $p$-coumaric acids) using cheap carbon sources such as glucose. For other phenolic acids, biosynthesis is still challenging, and the product titers should be at least 10-fold higher for economically feasible production. In some cases (e.g., for ferulic or vanilic acids), enzymatic conversion or bio-refining can be a more promising approach. For some phenolic acids, especially gentisic, syringic, sinapic, and caffeic acids, plants remain as the best source. Production of phenolic acids such as isovanillic, everninic, $o$ - and $m$-coumaric acids, and $\beta$-resorcylic acids is still not possible by microbial cell factories. Although phenolic acids such as $p$-hydroxybenzoic acid, $p$-coumaric acid, caffeic acid, vanillic acid, gallic acid, syringic acid, and ferulic acid can be used directly in various applications, their value can be significantly increased when they are further modified to high value-added compounds [305]. During the past few years, the production of value-added compounds from natural sources has gained tremendous importance.

Besides classic analytical techniques, biosensors can also be applied for quantitative analysis of phenolic acids. Nowadays, the use of TF-based biosensors is also an attractive method; however, such sensors are restricted to certain phenolic acids, which shows the need for TF based on other phenolic acids. Among the emerging production techniques, biotechnology-based generation using fermentation of genetically engineered microorganisms shows great potential as an alternative to the current manufacturing systems and has actually been applied for the industrial supply of bioactive compounds. There is a strong future drive to screen and engineer microbial strains for phenolic acid production through improving carbon-flux, enzymes bioactivity, and creating synthetic pathways for phenolic acid biosynthesis. These tasks are of great importance, and they can be solved by employing multiple disciplines such as chemistry, biology, process engineering, and computational biology.

Supplementary Materials: The following are available online at http://www.mdpi.com/2218-273X/10/6/874/s1, Table S1: Phenolic acid production in genetically engineered bacteria, yeasts, and fungi.

Author Contributions: Conceptualisation, E.V. and N.M.; data collection, E.V., writing-original draft preparation, E.V. and N.M.; writing-review and editing, E.V., I.J., M.S., E.A., P.M., A.S., and N.M.; visualisation, E.V. and N.M., supervision, N.M. All authors have read and agreed to the published version of the manuscript.

Funding: This research was funded by the European Regional Development Fund (project no. 01.2.2-LMT-K718-02-0023) under grant agreement with the Research Council of Lithuania (LMTLT). 
Conflicts of Interest: The authors declare no conflict of interest.

\section{References}

1. Kumar, N.; Goel, N. Phenolic acids: Natural versatile molecules with promising therapeutic applications. Biotechnol. Rep. 2019, 24, e00370. [CrossRef] [PubMed]

2. Khadem, S.; Marles, R.J. Monocyclic phenolic acids; hydroxy- and polyhydroxybenzoic acids: Occurrence and recent bioactivity studies. Molecules 2010, 15, 7985-8005. [CrossRef] [PubMed]

3. Martins, S.; Mussatto, S.I.; Martínez-Avila, G.; Montañez-Saenz, J.; Aguilar, C.N.; Teixeira, J.A. Bioactive phenolic compounds: Production and extraction by solid-state fermentation. A review. Biotechnol. Adv. 2011, 29, 365-373. [CrossRef]

4. Mandal, S.M.; Chakraborty, D.; Dey, S. Phenolic acids act as signaling molecules in plant-microbe symbioses. Plant Signal. Behav. 2010, 5, 359-368. [CrossRef] [PubMed]

5. Barros, J.; Escamilla-Trevino, L.; Song, L.; Rao, X.; Serrani-Yarce, J.C.; Palacios, M.D.; Engle, N.; Choudhury, F.K.; Tschaplinski, T.J.; Venables, B.J.; et al. 4-Coumarate 3-hydroxylase in the lignin biosynthesis pathway is a cytosolic ascorbate peroxidase. Nat. Commun. 2019, 10, 1994. [CrossRef] [PubMed]

6. Kulbat, K. The role of phenolic compounds in plant resistance. Biotechnol. Food Sci. 2016, 80, 97-108.

7. Cory, H.; Passarelli, S.; Szeto, J.; Tamez, M.; Mattei, J. The role of polyphenols in human health and food systems: A mini-review. Front. Nutr. 2018, 5, 87. [CrossRef]

8. Martin, K.R.; Appel, C.L. Polyphenols as dietary supplements: A double-edged sword. Nutr. Diet. Suppl. 2010, 2, 1-12. [CrossRef]

9. Crozier, A.; Jaganath, I.B.; Clifford, M.N. Dietary phenolics: Chemistry, bioavailability and effects on health. Nat. Prod. Rep. 2009, 26, 965-1096. [CrossRef]

10. Bhattacharya, A.; Sood, P.; Citovsky, V. The roles of plant phenolics in defence and communication during Agrobacterium and Rhizobium infection. Mol. Plant Pathol. 2010, 11, 705-719. [CrossRef]

11. Pereira, D.M.; Valentão, P.; Pereira, J.A.; Andrade, P.B. Phenolics: From chemistry to biology. Molecules 2009, 14, 2202-2211. [CrossRef]

12. de Camargo, A.C.; Regitano-d'Arce, M.A.B.; Rasera, G.B.; Canniatti-Brazaca, S.G.; do Prado-Silva, L.; Alvarenga, V.O.; Sant'Ana, A.S.; Shahidi, F. Phenolic acids and flavonoids of peanut by-products: Antioxidant capacity and antimicrobial effects. Food Chem. 2017, 237, 538-544. [CrossRef] [PubMed]

13. Binutu, O.A.; Cordell, G.A. Gallic acid derivatives from mezoneuron benthamianum leaves. Pharm. Biol. 2011, 38, 284-286. [CrossRef]

14. Pei, K.; Ou, J.; Huang, J.; Ou, S. p-Coumaric acid and its conjugates: Dietary sources, pharmacokinetic properties and biological activities. J. Sci. Food Agric. 2016, 96, 2952-2962. [CrossRef] [PubMed]

15. Ferreira, J.F.S.; Luthria, D.L.; Sasaki, T.; Heyerick, A. Flavonoids from Artemisia annua L. as antioxidants and their potential synergism with artemisinin against malaria and cancer. Molecules 2010, 15, 3135-3170. [CrossRef]

16. Wani, B.A.; Bodha, R.H.; Wani, A.H. Nutritional and medicinal importance of mushrooms. J. Med. Plants Res. 2010, 4, 2598-2604.

17. Lodovici, M.; Guglielmi, F.; Meoni, M.; Dolara, P. Effect of natural phenolic acids on DNA oxidation in vitro. Food Chem. Toxicol. 2001, 39, 1205-1210. [CrossRef]

18. Itoh, A.; Isoda, K.; Kondoh, M.; Kawase, M.; Watari, A.; Kobayashi, M.; Yagi, K. Hepatoprotective effect of syringic acid and vanillic acid on $\mathrm{CCl}_{4}$-induced liver injury. Biol. Pharm. Bull. 2010, 33, 983-987. [CrossRef]

19. Muthukumaran, J.; Srinivasan, S.; Venkatesan, R.S.; Ramachandran, V.; Muruganathan, U. Syringic acid, a novel natural phenolic acid, normalizes hyperglycemia with special reference to glycoprotein components in experimental diabetic rats. J. Acute Dis. 2013, 2, 304-309. [CrossRef]

20. Pinto, P.C.R.; Costa, C.E.; Rodrigues, A.E. Oxidation of lignin from Eucalyptus globulus pulping liquors to produce syringaldehyde and vanillin. Ind. Eng. Chem. Res. 2013, 52, 4421-4428. [CrossRef]

21. Mansouri, M.T.; Naghizadeh, B.; Ghorbanzadeh, B.; Farbood, Y.; Sarkaki, A.; Bavarsad, K. Gallic acid prevents memory deficits and oxidative stress induced by intracerebroventricular injection of streptozotocin in rats. Pharmacol. Biochem. Behav. 2013, 111, 90-96. [CrossRef] [PubMed] 
22. Yang, D.J.; Moh, S.H.; Son, D.H.; You, S.; Kinyua, A.W.; Ko, C.M.; Song, M.; Yeo, J.; Choi, Y.-H.; Kim, K.W. Gallic acid promotes wound healing in normal and hyperglucidic conditions. Molecules 2016, $21,899$. [CrossRef] [PubMed]

23. Park, H.J.; Cho, J.H.; Hong, S.H.; Kim, D.H.; Jung, H.Y.; Kang, I.K.; Cho, Y.J. Whitening and anti-wrinkle activities of ferulic acid isolated from Tetragonia tetragonioides in B16F10 melanoma and CCD-986sk fibroblast cells. J. Nat. Med. 2018, 72, 127-135. [CrossRef] [PubMed]

24. Kumar, K.J.S.; Vani, M.G.; Wang, S.-Y.; Liao, J.-W.; Hsu, L.-S.; Yang, H.-L.; Hseu, Y.-C. In vitro and in vivo studies disclosed the depigmenting effects of gallic acid: A novel skin lightening agent for hyperpigmentary skin diseases. BioFactors 2013, 39, 259-270. [CrossRef]

25. GMI. Salicylic acid Market Size, Industry Analysis Report, Regional Outlook, Application Development Potential, Price Trends, Competitive Market Share E Forecast, 2020-2026; Global Market Insights: Selbyville, DE, USA, 2020.

26. GMI. Natural Ferulic Acid Market Size by Purity, Industry Analysis Report, Regional Outlook, Application Potential, Price Trends, Competitive Market Share \& Forecast, 2019-2025; Global Market Insight: Selbyville, DE, USA, 2019.

27. Ou, S.; Kwok, K.C. Ferulic acid: Pharmaceutical functions, preparation and applications in foods. J. Sci. Food Agric. 2004, 84, 1261-1269. [CrossRef]

28. PMR. Gallic Acid Market-Global Industry Analysis 2014-2018 and Forecast 2019-2029; Persistence Market Research: New York, NY, USA, 2020.

29. IMR. Global Vanillic Acid (CAS 121-34-6) Market Analysis 2013-2018 and Forecast 2019-2024; Index Market Research: New York, NY, USA, 2019.

30. Solopova, A.; van Tilburg, A.Y.; Foito, A.; Allwood, J.W.; Stewart, D.; Kulakauskas, S.; Kuipers, O.P. Engineering Lactococcus lactis for the production of unusual anthocyanins using tea as substrate. Metab. Eng. 2019, 54, 160-169. [CrossRef]

31. Gottardi, M.; Knudsen, J.D.; Prado, L.; Oreb, M.; Branduardi, P.; Boles, E. De novo biosynthesis of trans-cinnamic acid derivatives in Saccharomyces cerevisiae. Appl. Microbiol. Biotechnol. 2017, 101, 4883-4893. [CrossRef]

32. Russell, W.R.; Labat, A.; Scobbie, L.; Duncan, G.J.; Duthie, G.G. Phenolic acid content of fruits commonly consumed and locally produced in Scotland. Food Chem. 2009, 115, 100-104. [CrossRef]

33. Kornsteiner, M.; Wagner, K.-H.; Elmadfa, I. Tocopherols and total phenolics in 10 different nut types. Food Chem. 2006, 98, 381-387. [CrossRef]

34. Bach, F.; Zielinski, A.A.F.; Helm, C.V.; Maciel, G.M.; Pedro, A.C.; Stafussa, A.P.; Ávila, S.; Haminiuk, C.W.I. Bio compounds of edible mushrooms: In vitro antioxidant and antimicrobial activities. LWT 2019, 107, 214-220. [CrossRef]

35. Karamaæ, M.; Kosiñska, A.; Pegg, R.B. Comparison of radical-scavenging activities. Pol. J. Food Nutr. Sci. 2005, 55, 165-170.

36. Ali, H.M.; Abo-Shady, A.; Eldeen, H.A.S.; Soror, H.A.; Shousha, W.G.; Abdel-Barry, O.A.; Saleh, A.M. Structural features, kinetics and SAR study of radical scavenging and antioxidant activities of phenolic and anilinic compounds. Chem. Cent. J. 2013, 7, 53. [CrossRef] [PubMed]

37. Amorati, R.; Pedulli, G.F.; Cabrin, L.; Zambonin, L.; Landi, L. Solvent and pH effects on the antioxidant activity of caffeic and other phenolic acids. J. Agric. 2006, 54, 2932-2937. [CrossRef] [PubMed]

38. Kaewnarin, K.; Suwannarach, N.; Kumla, J.; Lumyong, S. Phenolic profile of various wild edible mushroom extracts from Thailand and their antioxidant properties, anti-tyrosinase and hyperglycaemic inhibitory activities. J. Funct. Foods 2016, 27, 352-364. [CrossRef]

39. Palafox-Carlos, H.; Gil-Chávez, J.; Sotelo-Mundo, R.R.; Namiesnik, J.; Gorinstein, S.; González-Aguilar, G.A. Antioxidant interactions between major phenolic compounds found in 'Ataulfo' mango pulp: Chlorogenic, gallic, protocatechuic and vanillic acids. Molecules 2012, 17, 12657-12664. [CrossRef] [PubMed]

40. Chen, C.-Y.; Milbury, P.E.; Lapsley, K.; Blumberg, J.B. Flavonoids from almond skins are bioavailable and act synergistically with vitamins $\mathrm{C}$ and $\mathrm{E}$ to enhance hamster and human LDL resistance to oxidation. J. Nutr. 2005, 135, 1366-1373. [CrossRef]

41. Yildiz, O.; Can, Z.; Laghari, A.Q.; Şahin, H.; Malkoç, M. Wild edible mushrooms as a natural source of phenolics and antioxidants. J. Food Biochem. 2015, 39, 148-154. [CrossRef]

42. Bontpart, T.; Marlin, T.; Vialet, S.; Guiraud, J.L.; Pinasseau, L.; Meudec, E.; Sommerer, N.; Cheynier, V.; Terrier, N. Two shikimate dehydrogenases, VvSDH3 and VvSDH4, are involved in gallic acid biosynthesis in grapevine. J. Exp. Bot. 2016, 67, 3537-3550. [CrossRef] 
43. Heleno, S.A.; Martins, A.; Queiroz, M.J.R.P.; Ferreira, I.C.F.R. Bioactivity of phenolic acids: Metabolites versus parent compounds: A review. Food Chem. 2015, 173, 501-513. [CrossRef]

44. Santos-Sánchez, N.F.; Salas-Coronado, R.; Hernández-Carlos, B.; Villanueva-Cañongo, C. Shikimic acid pathway in biosynthesis of phenolic compounds. In Plant Physiological Aspects of Phenolic Compounds; Soto-Hernández, M., García-Mateos, R., Palma-Tenango, M., Eds.; IntechOpen: London, UK, 2019.

45. Serrano, M.; Wang, B.; Aryal, B.; Garcion, C.; Abou-Mansour, E.; Heck, S.; Geisler, M.; Mauch, F.; Nawrath, C.; Métraux, J.P. Export of salicylic acid from the chloroplast requires the multidrug and toxin extrusion-like transporter EDS5. Plant Physiol. 2013, 162, 1815-1821. [CrossRef]

46. Werner, R.A.; Rossmann, A.; Schwarz, C.; Bacher, A.; Schmidt, H.-L.; Eisenreich, W. Biosynthesis of gallic acid in Rhus typhina: Discrimination between alternative pathways from natural oxygen isotope abundance. Phytochemistry 2004, 65, 2809-2813. [CrossRef] [PubMed]

47. Widhalm, J.R.; Dudareva, N. A Familiar ring to it: Biosynthesis of plant benzoic acids. Mol. Plant 2015, 8, 83-97. [CrossRef] [PubMed]

48. Boatright, J.; Negre, F.; Chen, X.; Kish, C.M.; Wood, B.; Peel, G.; Orlova, I.; Gang, D.; Rhodes, D.; Dudareva, N. Understanding in vivo benzenoid metabolism in petunia petal tissue. Plant Physiol. 2004, 135, 1993-2011. [CrossRef] [PubMed]

49. Jarvis, A.P.; Schaaf, O.; Oldham, N.J. 3-hydroxy-3-phenylpropanoic acid is an intermediate in the biosynthesis of benzoic acid and salicylic acid but benzaldehyde is not. Planta 2000, 212, 119-126. [CrossRef] [PubMed]

50. Malinowski, J.; Krzymowska, M.; Godoń, K.; Hennig, J.; Podstolski, A. A new catalytic activity from tobacco converting 2-coumaric acid to salicylic aldehyde. Physiol. Plant. 2007, 129, 461-471. [CrossRef]

51. El-Basyquni, S.Z.; Chen, D.; Ibrahim, R.K.; Neish, A.C.; Towers, G.H.N. The biosynthesis of hydroxybenzoic acids in higher plants. Phytochemistry 1964, 3, 485-492. [CrossRef]

52. Batista, A.N.L.; Batista, J.M., Jr.; Souza-Moreira, T.M.; Valentini, S.R.; Kato, M.J.; Zanelli, C.F.; Furlan, M. Biosynthetic insights into p-hydroxybenzoic acid-derived benzopyrans in Piper gaudichaudianum. J. Braz. Chem. Soc. 2018, 29, 1105-1114. [CrossRef]

53. Hagel, P.; Kindl, H. p-Hydroxybenzoate synthase: A complex associated with mitochondrial membranes of roots Cucumis sativus. Febs Lett. 1975, 59, 120-124. [CrossRef]

54. Ribnicky, D.M.; Shulaev, V.; Raskin, I. Intermediates of salicylic acid biosynthesis in tobacco. Plant Physiol. 1998, 118, 565-572. [CrossRef]

55. Torrens-Spence, M.P.; Bobokalonova, A.; Carballo, V.; Glinkerman, C.M.; Pluskal, T.; Shen, A.; Weng, J.-K. PBS3 and EPS1 complete salicylic acid biosynthesis from isochorismate in Arabidopsis. Mol. Plant 2019, 12, 1577-1586. [CrossRef]

56. Catinot, J.; Buchala, A.; Abou-Mansour, E.; Métraux, J.-P. Salicylic acid production in response to biotic and abiotic stress depends on isochorismate in Nicotiana benthamiana. Febs Lett. 2008, 582, 473-478. [CrossRef] [PubMed]

57. Zhang, K.; Halitschke, R.; Yin, C.; Liu, C.-J.; Gan, S.-S. Salicylic acid 3-hydroxylase regulates Arabidopsis leaf longevity by mediating salicylic acid catabolism. Proc. Natl. Acad. Sci. USA 2013, 110, 14807-14812. [CrossRef] [PubMed]

58. Czichi, U.; Kindl, H. Phenylalanine ammonia lyase and cinnamic acid hydroxylases as assembled consecutive enzymes on microsomal membranes of cucumber cotyledons: Cooperation and subcellular distribution. Planta 1977, 134, 133-143. [CrossRef] [PubMed]

59. Ipson, B.R.; Fisher, A.L. Roles of the tyrosine isomers meta-tyrosine and ortho-tyrosine in oxidative stress. Ageing Res. Rev. 2016, 27, 93-107. [CrossRef]

60. Neish, A.C. Formation of $\mathrm{m}$ - and $\mathrm{p}$-coumaric acids by enzymatic deamination of the corresponding isomers of tyrosine. Phytochemistry 1961, 1, 1-24. [CrossRef]

61. Huang, T.; Rehak, L.; Jander, G. meta-Tyrosine in Festuca rubra ssp. commutata (Chewingsfescue) is synthesized by hydroxylation of phenylalanine. Phytochemistry 2012, 75, 60-66. [CrossRef]

62. Vialart, G.; Hehn, A.; Olry, A.; Ito, K.; Krieger, C.; Larbat, R.; Paris, C.; Shimizu, B.; Sugimoto, Y.; Mizutani, M.; et al. A 2-oxoglutarate-dependent dioxygenase from Ruta graveolens L. exhibits $p$-coumaroyl CoA 2'-hydroxylase activity $\left(\mathrm{C} 2^{\prime} \mathrm{H}\right)$ : A missing step in the synthesis of umbelliferone in plants. Plant J. 2011, 70, 460-470. [CrossRef] 
63. Taura, F.; Iijima, M.; Yamanaka, E.; Takahashi, H.; Kenmoku, H.; Saeki, H.; Morimoto, S.; Asakawa, Y.; Kurosaki, F.; Morita, H. A novel class of plant type III polyketide synthase involved in orsellinic acid biosynthesis from Rhododendron dauricum. Front. Plant Sci. 2016, 7, 1452. [CrossRef]

64. Dey, T.B.; Chakraborty, S.; Jain, K.K.; Sharma, A.; Kuhad, R.C. Antioxidant phenolics and their microbial production by submerged and solid state fermentation process: A review. Trends Food Sci. Technol. 2016, 53, 60-74.

65. Herrmann, K.; Nagel, C.W. Occurrence and content of hydroxycinnamic and hydroxybenzoic acid compounds in foods. Crit. Rev. Food Sci. Nutr. 1989, 28, 315-347. [CrossRef]

66. Cai, Z.; Kastell, A.; Knorr, D.; Smetanska, I. Exudation: An expanding technique for continuous production and release of secondary metabolites from plant cell suspension and hairy root cultures. Plant Cell Rep. 2012, 31, 461-477. [CrossRef] [PubMed]

67. Enebe, M.C.; Babalola, O.O. The impact of microbes in the orchestration of plants' resistance to biotic stress: A disease management approach. Appl. Microbiol. Biotechnol. 2019, 103, 9-25. [CrossRef] [PubMed]

68. Nanda, A.K.; Andrio, E.; Marino, D.; Pauly, N.; Dunand, C. Reactive oxygen species during plant-microorganism early interactions. J. Integr. Plant Biol. 2010, 52, 195-204. [CrossRef] [PubMed]

69. Gonugunta, V.K.; Srivastava, N.; Raghavendra, A.S. Cytosolic alkalinization is a common and early messenger preceding the production of ROS and NO during stomatal closure by variable signals, including abscisic acid, methyl jasmonate and chitosan. Plant Signal. Behav. 2009, 4, 561-564. [CrossRef]

70. El-Shetehy, M.; Wang, C.; Shine, M.B.; Yu, K.; Kachroo, A.; Kachroo, P. Nitric oxide and reactive oxygen species are required for systemic acquired resistance in plants. Plant Signal. Behav. 2015, 10, e998544. [CrossRef]

71. Zheng, X.Y.; Zhou, M.; Yoo, H.; Pruneda-Paz, J.L.; Spivey, N.W.; Kay, S.A.; Dong, X. Spatial and temporal regulation of biosynthesis of the plant immune signal salicylic acid. Proc. Natl. Acad. Sci. USA 2015, 112, 9166-9173. [CrossRef]

72. Forouhar, F.; Yang, Y.; Kumar, D.; Chen, Y.; Fridman, E.; Park, S.W.; Chiang, Y.; Acton, T.B.; Montelione, G.T.; Pichersky, E.; et al. Structural and biochemical studies identify tobacco SABP2 as a methyl salicylate esterase and implicate it in plant innate immunity. PNAS 2005, 102, 1773-1778. [CrossRef]

73. Park, S.W.; Kaimoyo, E.; Kumar, D.; Mosher, S.; Klessig, D.F. Methyl salicylate is a critical mobile signal for plant systemic acquired resistance. Science 2007, 318, 113-116. [CrossRef]

74. Zander, M.; Thurow, C.; Gatz, C. TGA transcription factors activate the salicylic acid-suppressible branch of the ethylene-induced defense program by regulating $O R A_{59}$ expression. Plant Physiol. 2014, 165, 1671-1683. [CrossRef]

75. Schmiesing, A.; Emonet, A.; Gouhier-Darimont, C.; Reymond, P. Arabidopsis MYC transcription factors are the target of hormonal salicylic acid/jasmonic acid cross talk in response to Pieris brassicae egg extract. Plant Physiol. 2016, 170, 2432-2443. [CrossRef]

76. Caarls, L.; Van der Does, D.; Hickman, R.; Jansen, W.; Van Verk, M.C.; Proietti, S.; Lorenzo, O.; Solano, R.; Pieterse, C.M.J.; Van Wees, S.C.M. Assessing the role of ethylene response factor transcriptional repressors in salicylic acid-mediated suppression of jasmonic acid-responsive genes. Plant Cell Physiol. 2017, 58, 266-278. [CrossRef] [PubMed]

77. Huang, Y.F.; Chen, C.T.; Kao, C.H. Salicylic acid inhibits the biosynthesis of ethylene in detached rice leaves. Plant Growth Regul. 1993, 12, 79-82. [CrossRef]

78. Zhu, J.-K. Abiotic stress signaling and responses in plants. Cell 2016, 167, 313-324. [CrossRef]

79. Tuteja, N. Abscisic acid and abiotic stress signaling. Plant Signal. Behav. 2007, 2, 135-138. [CrossRef] [PubMed]

80. Jain, A.; Singh, A.; Singh, S.; Singh, H.B. Phenols enhancement effect of microbial consortium in pea plants restrains Sclerotinia sclerotiorum. Biol. Control 2015, 89, 23-32. [CrossRef]

81. Linić, I.; Šamec, D.; Grúz, J.; Bok, V.V.; Strnad, M.; Salopek-Sondi, B. Involvement of phenolic acids in short-term adaptation to salinity stress is species-specific among Brassicaceae. Plants 2019, 8, 155. [CrossRef]

82. Jahangir, M.; Abdel-Farid, I.B.; Choi, Y.H.; Verpoorte, R. Metal ion-inducing metabolite accumulation in Brassica rapa. J. Plant Physiol. 2008, 165, 1429-1437. [CrossRef]

83. Stelzner, J.; Roemhild, R.; Garibay-Hernández, A.; Harbaum-Piayda, B.; Mock, H.-P.; Wolfgang Bilger, W. Hydroxycinnamic acids in sunflower leaves serve as UV-A screening pigments. Photochem. Photobiol. Sci. 2019, 18, 1649-1659. [CrossRef] 
84. Jacobo-Velázquez, D.A.; Martínez-Hernández, G.B.; Del, C.; Rodríguez, S.; Cao, C.M.; Cisneros-Zevallos, L. Plants as biofactories: Physiological role of reactive oxygen species on the accumulation of phenolic antioxidants in carrot tissue under wounding and hyperoxia stress. J. Agric. Food Chem. 2011, 59, 6583-6593. [CrossRef]

85. Heredia, J.B.; Cisneros-Zevallos, L. The effect of exogenous ethylene and methyl jasmonate on pal activity, phenolic profiles and antioxidant capacity of carrots (Daucus carota) under different wounding intensities. Postharvest Biol. Technol. 2009, 51, 242-249. [CrossRef]

86. Ayaz, F.A.; Kadioglu, A.; Turgut, R. Water stress effects on the content of low molecular weight carbohydrates and phenolic acids in Ctenanthe setosa (Rosc.) Eichler. Can. J. Plant Sci. 2000, 80, 373-378. [CrossRef]

87. Haskins, F.A.; Williams, L.G.; Gorz, H.J. Light-induced trans to cis conversion of $\beta$-d-glucosyl o-hydroxycinnamic acid in Melilotus alba leaves. Plant Physiol. 1964, 39, 777-781. [CrossRef] [PubMed]

88. Değirmencioğlu, N.; Gürbüz, O.; Karatepe, G.E.; Irkin, R. Influence of hot air drying on phenolic compounds and antioxidant capacity of blueberry (Vaccinium myrtillus) fruit and leaf. J. Appl. Bot. Food Qual. 2017, 90, 115-125.

89. Brereton, N.J.B.; Berthod, N.; Lafleur, B.; Pedneault, K.; Pitre, F.E.; Labrecque, M. Extractable phenolic yield variation in five cultivars of mature short rotation coppice willow from four plantations in Quebec. Ind. Crop. Prod. 2017, 97, 525-535. [CrossRef]

90. Cardozo, E.L.; Ferrarese-Filho, O.; Filho, L.C.; Ferrarese, M.L.L.; Donaduzzi, C.M.; Sturion, J.A. Methylxanthines and phenolic compounds in mate (Ilex paraguariensis St. Hil.) progenies grown in Brazil. J. Food Compos. Anal. 2007, 20, 553-558. [CrossRef]

91. Kivilompolo, M.; Hyotylainen, T. Comprehensive two-dimensional liquid chromatography in analysis of Lamiaceae herbs: Characterisation and quantification of antioxidant phenolic acids. J. Chromatogr. A 2007, 1145, 155-164. [CrossRef]

92. Złotek, U.; Gawlik-Dziki, U.; Dziki, D.; Świeca, M.; Nowak, R.; Martinez, E. Influence of drying temperature on phenolic acids composition and antioxidant activity of sprouts and leaves of white and red Quinoa. J. Chem. 2019, 2019, 8. [CrossRef]

93. Prabakaran, M.; Lee, J.-H.; Ahmad, A.; Kim, S.-H.; Woo, K.-S.; Kim, M.-J.; Chung, I.-M. Effect of storage time and temperature on phenolic compounds of soybean (Glycine max L.) flour. Molecules 2018, 23, 2269. [CrossRef]

94. Khattab, R.; Eskin, M.; Aliani, M.; Thiyam, U. Determination of sinapic acid derivatives in canola extracts using high-performance liquid chromatography. J. Am. Oil Chem. Soc. 2010, 87, 147-155. [CrossRef]

95. Ozer, H.K. Phenolic compositions and antioxidant activities of Maya nut (Brosimum alicastrum): Comparison with commercial nuts. Int. J. Food Prop. 2017, 20, 2772-2781. [CrossRef]

96. Sampaio, C.R.P.; Hamerski, F.; Ribani, R.H. Antioxidant phytochemicals of Byrsonima ligustrifolia throughout fruit developmental stages. J. Funct. Foods 2015, 18, 400-410. [CrossRef]

97. Mattila, P.; Hellström, J.; Törrönen, R. Phenolic acids in berries, fruits, and beverages. J. Agric. Food Chem. 2006, 54, 7193-7199. [CrossRef] [PubMed]

98. Mallek-Ayadi, S.; Bahloul, N.; Kechaou, N. Characterization, phenolic compounds and functional properties of Cucumis melo L. peels. Food Chem. 2017, 221, 1691-1697. [CrossRef] [PubMed]

99. Zadernowski, R.; Czaplicki, S.; Naczk, M. Phenolic acid profiles of mangosteen fruits (Garcinia mangostana). Food Chem. 2009, 112, 685-689. [CrossRef]

100. Chon, S.-U.; Kim, Y.-M. Herbicidal potential and quantification of suspected allelochemicals from four grass crop extracts. J. Agron. Crop Sci. 2004, 190, 145-150. [CrossRef]

101. Caldas, T.W.; Mazza, K.E.L.; Teles, A.S.C.; Mattos, G.N.; Brígidac, A.I.S.; Conte-Junior, C.A.; Borguinic, R.G.; Godoy, R.L.O.; Cabral, L.M.C.; Tonon, R.V. Phenolic compounds recovery from grape skin using conventional and non-conventional extraction methods. Ind. Crop. Prod. 2018, 111, 86-91. [CrossRef]

102. Foo, S.C.; Yusoff, F.M.; Ismail, M.; Basri, M.; Yau, S.K.; Khong, N.M.H.; Chan, K.W.; Ebrahimi, M. Antioxidant capacities of fucoxanthin-producing algae as influenced by their carotenoid and phenolic contents. J. Biotechnol. 2017, 241, 175-183. [CrossRef]

103. Shan, B.; Cai, Y.Z.; Sun, M.; Corke, H. Antioxidant capacity of 26 spice extracts and characterization of their phenolic constituents. J. Agric. Food Chem. 2005, 53, 7749-7759. [CrossRef] 
104. Bae, I.K.; Ham, H.M.; Jeong, M.H.; Kim, D.H.; Kim, H.J. Simultaneous determination of 15 phenolic compounds and caffeine in teas and mate using RP-HPLC/UV detection: Method development and optimization of extraction process. Food Chem. 2015, 172, 469-475. [CrossRef]

105. Deng, G.F.; Shen, C.; Xu, X.R.; Kuang, R.D.; Guo, Y.J.; Zeng, L.S.; Gao, L.L.; Lin, X.; Xie, J.F.; Xia, E.Q.; et al. Potential of fruit wastes as natural resources of bioactive compounds. Int. J. Mol. Sci. 2012, 13, 8308-8323. [CrossRef]

106. Silva-Beltrán, N.P.; Chaidez-Quiroz, C.; López-Cuevas, O.; Ruiz-Cruz, S.; López-Mata, M.A.; Del-Toro-Sánchez, C.L.; Marquez-Rios, E.; Ornelas-Paz, J.d.J. Phenolic compounds of potato peel extracts: Their antioxidant activity and protection against human enteric viruses. J. Microbiol. Biotechnol. 2017, 27, 234-241. [CrossRef] [PubMed]

107. Martínez-Cruz, O.; Paredes-López, O. Phytochemical profile and nutraceutical potential of chia seeds (Salvia hispanica L.) by ultra high performance liquid chromatography. J. Chromatogr. A 2014, 1346, 43-48.

108. Prakash, D.; Singh, B.N.; Upadhyay, G. Antioxidant and free radical scavenging activities of phenols from onion (Allium cepa). Food Chem. 2007, 102, 1389-1393. [CrossRef]

109. Arruda, H.S.; Pereira, G.A.; de Morais, D.R.; Eberlin, M.N.; Pastore, G.M. Determination of free, esterified, glycosylated and insoluble-bound phenolics composition in the edible part of araticum fruit (Annona crassiflora Mart.) and its by-products by HPLC-ESI-MS/MS. Food Chem. 2018, 245, 738-749. [CrossRef] [PubMed]

110. Zgórka, G.; Głowniak, K. Variation of free phenolic acids in medicinal plants belonging to the Lamiaceae family. J. Pharm. Biomed. Anal. 2001, 26, 79-87. [CrossRef]

111. Lu, M.; Yuan, B.; Zeng, M.; Chen, J. Antioxidant capacity and major phenolic compounds of spices commonly consumed in China. Food Res. Int. 2011, 44, 530-536. [CrossRef]

112. Chandrasekara, N.; Shahidi, F. Effect of roasting on phenolic content and antioxidant activities of whole cashew nuts, kernels, and testa. J. Agric. Food Chem. 2011, 59, 5006-5014. [CrossRef] [PubMed]

113. Karasová, G.; Lehotay, J. Chromatographic determination of derivatives of $p$-hydroxybenzoic acid in Melissa officinalis by HPLC. J. Liq. Chromatogr. Relat. Technol. 2005, 28, 2421-2431. [CrossRef]

114. Budrat, P.; Shotipruk, A. Enhanced recovery of phenolic compounds from bitter melon (Momordica charantia) by subcritical water extraction. Sep. Purif. Technol. 2009, 66, 125-129. [CrossRef]

115. Aresta, A.; Zambonin, C. Simultaneous determination of salicylic, 3-methyl salicylic, 4-methyl salicylic, acetylsalicylic and benzoic acids in fruit, vegetables and derived beverages by SPME-LC-UV/DAD. J. Pharm. Biomed. Anal. 2016, 121, 63-68. [CrossRef]

116. Tian, Y.; Liimatainen, J.; Alanne, A.-L.; Lindstedt, A.; Liu, P.; Sinkkonen, J.; Kallio, H.; Yang, B. Phenolic compounds extracted by acidic aqueous ethanol from berries and leaves of different berry plants. Food Chem. 2017, 220, 266-281. [CrossRef] [PubMed]

117. Wojdyło, A.; Oszmiański, J.; Czemerys, R. Antioxidant activity and phenolic compounds in 32 selected herbs. Food Chem. 2007, 105, 940-949. [CrossRef]

118. Prabakaran, M.; Kim, S.-H.; Hemapriya, V.; Chung, I.-M. Evaluation of polyphenol composition and anti-corrosion properties of Cryptostegia grandiflora plant extract on mild steel in acidic medium. J. Ind. Eng. Chem. 2016, 37, 47-56. [CrossRef]

119. Prabakaran, M.; Kim, S.-H.; Sasireka, A.; Chandrasekaran, M.; Chung, I.-M. Polyphenol composition and antimicrobial activity of various solvent extracts from different plant parts of Moringa oleifera. Food Biosci. 2018, 26, 23-29. [CrossRef]

120. Chung, I.M.; Kim, K.H.; Ahn, J.K.; Chun, S.C.; Kim, S.C.; Kim, J.T.; Kim, S.H. Screening of allelochemicals on barnyardgrass (Echinochloa crus-galli) and identification of potentially allelopathic compounds from rice (Oryza sativa) variety hull extracts. Crop Prot. 2002, 21, 913-920. [CrossRef]

121. Barron, C.; Surget, A.; Rouau, X. Relative amounts of tissues in mature wheat (Triticum aestivum L.) grain and their carbohydrate and phenolic acid composition. J. Cereal Sci. 2007, 45, 88-96. [CrossRef]

122. Kim, K.-H.; Tsao, R.; Yang, R.; Cui, S.W. Phenolic acid profiles and antioxidant activities of wheat bran extracts and the effect of hydrolysis conditions. Food Chem. 2006, 95, 466-473. [CrossRef]

123. Lemos, M.R.B.; de Almeida Siqueira, E.M.; Arruda, S.F.; Zambiazi, R.C. The effect of roasting on the phenolic compounds and antioxidant potential of baru nuts [Dipteryx alata Vog.]. Food Res. Int. 2012, 48, 592-597. [CrossRef] 
124. Kerienè, I.; Mankevičienè, A.; Bliznikas, S.; Jablonskytė-Raščè, D.; Maikštenienè, S.; Česnuliavičienė, R. Biologically active phenolic compounds in buckwheat, oats and winter spelt wheat. Zemdirb. -Agric. 2015, 102, 289-296.

125. Brouns, F.; Hemery, Y.; Price, R.; Anson, N.M. Wheat aleurone: Separation, composition, health aspects, and potential food use. Crit. Rev. Food Sci. Nutr. 2012, 52, 553-568. [CrossRef]

126. Mccallum, J.A.; Walker, J.R.L. Phenolic biosynthesis during grain development in wheat (Triticum aestivum L.) III. Changes in hydroxycinnamic acids during grain development. J. Cereal Sci. 1991, 13, 161-172. [CrossRef]

127. Karamać, M.; Kosińska, A.; Estrella, I.; Hernández, T.; Dueñas, M. Antioxidant activity of phenolic compounds identified in sunflower seeds. Eur. Food Res. Technol. 2012, 235, 221-230. [CrossRef]

128. Waszkowiak, K.; Gliszczyńska-Świgło, A.; Barthet, V.; Skręty, J. Effect of extraction method on the phenolic and cyanogenic glucoside profile of flaxseed extracts and their antioxidant capacity. J. Am. Oil Chem. Soc. 2015, 92, 1609-1619. [CrossRef] [PubMed]

129. Jun, H.-I.; Wiesenborn, D.P.; Kim, Y.-S. Antioxidant activity of phenolic compounds from canola (Brassica napus) seed. Food Sci. Biotechnol. 2014, 23, 1753-1760. [CrossRef]

130. Anwar, M.M.; Ali, S.E.; Nasra, E.H. Improving the nutritional value of canola seed by gamma irradiation. J. Radiat. Res. Appl. Sci. 2015, 8, 328-333. [CrossRef]

131. Diaconeasa, Z.; Florica, R.; Rugina, D.; Lucian, C.; Socaciu, C. HPLC/PDA-ESI/MS identification of phenolic acids, flavonol glycosides and antioxidant potential in blueberry, blackberry, raspberries and cranberries. J. Food Nutr. Res. 2014, 2, 781-785. [CrossRef]

132. Mahmood, T.; Anwar, F.; Abbas, M.; Saari, N. Effect of maturity on phenolics (phenolic acids and flavonoids) profile of strawberry cultivars and mulberry species from Pakistan. Int. J. Mol. Sci. 2012, 13, 4591-4607. [CrossRef]

133. Mattila, P.; Hellström, J. Phenolic acids in potatoes, vegetables, and some of their products. J. Food Compos. Anal. 2007, 20, 152-160. [CrossRef]

134. Akyol, H.; Riciputi, Y.; Capanoglu, E.; Caboni, M.F.; Verardo, V. Phenolic compounds in the potato and its byproducts: An overview. Int. J. Mol. Sci. 2016, 17, 835. [CrossRef]

135. Ferreres, F.; Gil, M.I.; Castañer, M.; Tomás-Barberán, F.A. Phenolic metabolites in red pigmented lettuce (Lactuca sativa). Changes with minimal processing and cold storage. J. Agric. Food Chem. 1997, 45, 4249-4254. [CrossRef]

136. Dao, L.; Friedman, M. Chlorogenic acid content of fresh and processed potatoes determined by ultraviolet spectrophotometry. J. Agric. Food Chem. 1992, 40, 2152-2156. [CrossRef]

137. Robbins, K.S.; Gong, Y.; Wells, M.L.; Greenspan, P.; Pegg, R.B. Investigation of the antioxidant capacity and phenolic constituents of U.S. pecans. J. Funct. Foods 2015, 15, 11-22. [CrossRef]

138. Alasalvar, C.; Bolling, B.W. Review of nut phytochemicals, fat-soluble bioactives, antioxidant components and health effect. Br. J. Nutr. 2015, 113, S68-S78. [CrossRef] [PubMed]

139. Milbury, P.E.; Chen, C.-Y.; Dolnikowski, G.G.; Blumberg, J.B. Determination of flavonoids and phenolics and their distribution in almonds. J. Agric. Food Chem. 2006, 54, 5027-5033. [CrossRef] [PubMed]

140. Bolling, B.W.; Blumberg, J.B.; Chen, C.-Y.O. The influence of roasting, pasteurisation, and storage on the polyphenol content and antioxidant capacity of California almond skins. Food Chem. 2010, 123, 1040-1047. [CrossRef] [PubMed]

141. Talcott, S.T; Duncan, C.E.; Pozo-Insfran, D.D.; Gorbet, D.W. Polyphenolic and antioxidant changes during storage of normal, mid, and high oleic acid peanuts. Food Chem. 2005, 89, 77-84. [CrossRef]

142. Ulewicz-Magulska, B.; Wesolowski, M. Total phenolic contents and antioxidant potential of herbs used for medical and culinary purposes. Plant Foods Hum. Nutr. 2019, 74, 61-67. [CrossRef]

143. Bahadori, M.B.; Asghari, B.; Dinparast, L.; Zengin, G.; Sarikurkcu, C.; Abbas-Mohammadi, M.; Bahadori, S. Salvia nemorosa L.: A novel source of bioactive agents with functional connections. LWT 2017, 75, 42-50. [CrossRef]

144. Górnas, P.; Dwiecki, K.; Siger, A.; Tomaszewska-Gras, J.; Michalak, M.; Polewski, K. Contribution of phenolic acids isolated from green and roasted boiled-type coffee brews to total coffee antioxidant capacity. Eur. Food Res. Technol. 2016, 242, 641-653. [CrossRef]

145. Perdani, C.G.; Pranowo, D.; Qonitatilah. Total phenols content of green coffee (Coffea arabica and Coffea canephora) in East Java. Iop Conf. Ser. Earth Environ. Sci. 2019, 230, 012093. [CrossRef] 
146. Sadh, P.K.; Duhan, S.; Duhan, J.S. Agro-industrial wastes and their utilization using solid state fermentation: A review. Bioresour. Bioprocess. 2018, 5, 1. [CrossRef]

147. Pfaltzgraff, L.A.; De bruyn, M.; Cooper, E.C.; Budarin, V.; Clark, J.H. Food waste biomass: A resource for high-value chemicals. Green Chem. 2013, 15, 307-314. [CrossRef]

148. Li, M.; Jia, Z.; Wan, G.; Wang, S.; Min, D. Enhancing isolation of p-coumaric and ferulic acids from sugarcane bagasse by sequential hydrolysis. Chem. Pap. 2020, 74, 499-507. [CrossRef]

149. Alhamad, M.N.; Rababah, T.M.; Al-u'datt, M.; Ereifej, K.; Esoh, R.; Feng, H.; Yang, W. The physicochemical properties, total phenolic, antioxidant activities, and phenolic profile of fermented olive cake. Arab. J. Chem. 2017, 10, 136-140. [CrossRef]

150. Wu, J.; Collins, S.R.A.; Elliston, A.; Wellner, N.; Dicks, J.; Roberts, I.N.; Waldron, K.W. Release of cell wall phenolic esters during hydrothermal pretreatment of rice husk and rice straw. Biotechnol. Biofuels 2018, 11, 162. [CrossRef] [PubMed]

151. Quinn, L.A.; Tang, H.H. Antioxidant properties of phenolic compounds in macadamia nuts. J. Am. Oil Chem. Soc. 1996, 73, 1585-1588. [CrossRef]

152. Amaya-Cruz, D.M.; Pérez-Ramírez, I.F.; Delgado-García, J.; Mondragón-Jacobo, C.; Dector-Espinoza, A.; Reynoso-Camacho, R. An integral profile of bioactive compounds and functional properties of prickly pear (Opuntia ficus indica L.) peel with different tonalities. Food Chem. 2019, 278, 568-578. [CrossRef]

153. Gómez-Mejía, E.; Rosales-Conrado, N.; León-González, M.E.; Madrid, Y. Citrus peels waste as a source of value-added compounds: Extraction and quantification of bioactive polyphenols. Food Chem. 2019, 289-299. [CrossRef]

154. Orhan, I.; Ustun, O. Determination of total phenol content, antioxidant activity and acetylcholinesterase inhibition in selected mushrooms from Turkey. J. Food Compos. Anal. 2011, 24, 386-390. [CrossRef]

155. Tepsongkroh, B.; Jangchud, K.; Trakoontivakorn, G. Antioxidant properties and selected phenolic acids of five different tray-dried and freeze-dried mushrooms using methanol and hot water extraction. J. Food Meas. Charact. 2019, 13, 3097-3105. [CrossRef]

156. Barros, L.; Dueñas, M.; Ferreira, I.C.F.R.; Baptista, P.; Santos-Buelga, C. Phenolic acids determination by HPLC-DAD-ESI/MS in sixteen different Portuguese wild mushrooms species. Food Chem. Toxicol. 2009, 47, 1076-1079. [CrossRef] [PubMed]

157. Heleno, S.A.; Barros, L.; Martins, A.; Queiroz, M.J.R.P.; Santos-Buelga, C.; Ferreira, I.C.F.R. Fruiting body spores and in vitro produced mycelium of Ganoderma lucidum from Northeast Portugal: A comparative study of the antioxidant potential of phenolic and polysaccharidic extracts. Food Res. Int. 2012, 46, 135-140. [CrossRef]

158. Reis, F.S.; Heleno, S.A.; Barros, L.; Sousa, M.J.; Martins, A.; SantosBuelga, C.; Ferreira, I.C.F.R. Toward the antioxidant and chemical characterization of mycorrhizal mushrooms from Northeast Portugal. J. Food Sci. 2011, 76, 824-830. [CrossRef] [PubMed]

159. Vaz, J.A.; Barros, L.; Martins, A.; Morais, J.S.; Vasconcelos, M.H.; Ferreira, I.C.F.R. Phenolic profile of seventeen Portuguese wild mushrooms. Lwt-Food Sci. Technol. 2011, 44, 343-346. [CrossRef]

160. Vaz, J.A.; Barros, L.; Martins, A.; Santos-Buelga, C.; Vasconcelos, M.H.; Ferreira, I.C.F.R. Chemical composition of wild edible mushrooms and antioxidant properties of their water soluble polysaccharidic and ethanolic fractions. Food Chem. 2011, 126, 610-616. [CrossRef]

161. Alves, M.J.; Ferreira, I.C.F.R.; Froufe, H.J.C.; Abreu, R.M.V.; Martins, A.; Pintado, M. Antimicrobial activity of phenolic compounds identified in wild mushrooms, SAR analysis and docking studies. J. Appl. Microbiol. 2013, 115, 346-357. [CrossRef] [PubMed]

162. Reis, F.S.; Martins, A.; Barros, L.; Ferreira, I.C.F.R. Antioxidant properties and phenolic profile of the most widely appreciated cultivated mushrooms: A comparative study between in vivo and in vitro samples. Food Chem. Toxicol. 2012, 50, 1201-1207. [CrossRef]

163. Bertrand, R.L.; Sorensen, J.L. A comprehensive catalogue of polyketide synthase gene clusters in lichenizing fungi. J. Ind. Microbiol. Biotechnol. 2018, 45, 1067-1081. [CrossRef]

164. Torres-Benítez, A.; Rivera-Montalvo, M.; Sepúlveda, B.; Olivio, N.; Castro, O.N.; Nagles, E.; Simirgiotis, M.J.; García-Beltrán, O.; Areche, C. Metabolomic analysis of two Parmotrema lichens: P. robustum (Degel.) hale and P. andinum (Mull. Arg.) hale using UHPLC-ESI-OT-MS-MS. Molecules 2017, 22, 1861. 
165. Jin, Y.; Ma, Y.; Xie, W.; Hou, L.; Xu, H.; Zhang, K.; Zhang, L.; Du, Y. UHPLC-Q-TOF-MS/MS-oriented characteristic components dataset and multivariate statistical techniques for the holistic quality control of Usnea. Rsc Adv. 2018, 8, 15487-15500. [CrossRef]

166. Lopes, T.I.B.; Coelho, R.G.; Yoshida, N.C.; Honda, N.K. Radical-scavenging activity of orsellinates. Chem. Pharm. Bull. 2008, 56, 1551-1554. [CrossRef] [PubMed]

167. Mukherjee, G.; Sachan, A.; Ghosh, S.; Mitra, A. Conversion of sinapic acid to syringic acid by a filamentous fungus Paecilomyces variotii. J. Gen. Appl. Microbiol. 2006, 52, 131-135. [CrossRef] [PubMed]

168. Ishikura, T.; Nishida, H.; Tanno, K.; Miyachi, N.; Ozaki, A. Microbial production of salicylic acid from naphthalene. Agric. Biol. Chem. 1968, 32, 12-20.

169. Gupta, D.; Sinha, S.N. Production of salicylic acid by a purple non sulfur bacterium Rubrivivax gelatinosus strain RASN4 from rhizosperic soil of paddy fields. J. Glob. Biosci. 2020, 9, 6718-6736.

170. Mishra, S.; Kullu, M.; Sachan, A.; Vidyarthi, A.S.; Sachan, S.G. Bioconversion of ferulic acid to vanillic acid by Paenibacillus lactis SAMS-2001. Ann. Microbiol. 2016, 66, 875-882. [CrossRef]

171. Vyrides, I.; Agathangelou, M.; Dimitriou, R.; Souroullas, K.; Salamex, A.; Ioannou, A.; Koutinas, M. Novel Halomonas sp. B15 isolated from Larnaca Salt Lake in Cyprus that generates vanillin and vanillic acid from ferulic acid. World J. Microbiol. Biotechnol. 2015, 31, 1291-1296. [CrossRef]

172. Tang, P.L.; Hassan, O. Bioconversion of ferulic acid attained from pineapple peels and pineapple crown leaves into vanillic acid and vanillin by Aspergillus niger I-1472. Bmc Chem. 2020, 14, 7. [CrossRef]

173. Topakas, E.; Kalogeris, E.; Kekos, D.; Macris, B.J.; Christakopoulos, P. Bioconversion of ferulic acid into vanillic acid by the thermophilic fungus Sporotrichum thermophile. Lwt Food Sci. Technol. 2003, 36, 561-565. [CrossRef]

174. Skóra, J.; Sulyok, M.; Nowak, A.; Otlewska, A.; Gutarowska, B. Toxinogenicity and cytotoxicity of Alternaria, Aspergillus and Penicillium moulds isolated from working environments. Int. J. Environ. Sci. Technol. Vol. 2017, 14, 595-608. [CrossRef]

175. Bajpai, B.; Patil, S. A new approach to microbial production of gallic acid. Braz. J. Microbiol. 2008, 39, 708-711. [CrossRef]

176. Fathy, S.A.; Mahmoud, A.E.; Rashad, M.M.; Ezz, M.K.; Mohammed, A.T. Improving the nutritive value of olive pomace by solid state fermentation of Kluyveromyces marxianus with simultaneous production of gallic acid. Int. J. Recycl. Org. Waste Agric. 2018, 7, 135-141. [CrossRef]

177. Limón, R.I.; Peñas, E.; Torino, M.I.; Martínez-Villaluenga, C.; Dueñas, M.; Frias, J. Fermentation enhances the content of bioactive compounds in kidney bean extracts. Food Chem. 2015, 72, 343-352. [CrossRef] [PubMed]

178. Schmidt, C.G.; Gonçalve, L.M.; Prietto, L.; Hackbart, H.S.; Furlong, E.B. Antioxidant activity and enzyme inhibition of phenolic acids from fermented rice bran with fungus Rizhopus oryzae. Food Chem. 2014, 146, 371-377. [CrossRef] [PubMed]

179. Banerjee, R.; Mukherjee, G.; Patra, K.C. Microbial transformation of tannin-rich substrate to gallic acid through co-culture method. Bioresour. Technol. 2005, 96, 949-953. [CrossRef]

180. Jamal, P.; Idris, Z.M.; Alam, M.Z. Effects of physicochemical parameters on the production of phenolic acids from palm oil mill effluent under liquid-state fermentation by Aspergillus niger IBS-103ZA. Food Chem. 2011, 124, 1595-1602. [CrossRef]

181. Sakamoto, T.; Nishimura, S.; Kato, T.; Sunagawa, Y.; Tsuchiyama, M.; Kawasaki, H. Efficient extraction of ferulic acid from sugar beet pulp using the culture supernatant of Penicillium chrysogenum. J. Appl. Glycosci. 2005, 52, 115-120. [CrossRef]

182. Daumy, G.O.; McColl, A.S.; Andrews, G.C. Bioconversion of $m$-hydroxybenzoate to 2,3-dihydroxybenzoate by mutants of Pseudomonas testosteroni. J. Bacteriol. 1980, 141, 293-296. [CrossRef]

183. Couto, S.R.; Sanroman, M.A. Application of solid-state fermentation to food industry-A review. J. Food Eng. 2006, 76, 291-302. [CrossRef]

184. Mitchell, D.A.; von Meien, O.F.; Krieger, N.; Dalsenter, F.D.H. A review of recent developments in modeling of microbial growth kinetics and intraparticle phenomena in solid-state fermentation. Biochem. Eng. J. 2004, 17, 15-26. [CrossRef]

185. Lambert, R.J.; Stratford, M. Weak-acid preservatives: Modelling microbial inhibition and response. J. Appl. Microbiol. 1999, 86, 157-164. [CrossRef] 
186. Mycroft, Z.; Gomis, M.; Mines, P.; Law, P.; Bugg, T.D.H. Biocatalytic conversion of lignin to aromatic dicarboxylic acids in Rhodococcus jostii RHA1 by re-routing aromatic degradation pathways. Green Chem. 2015, 17, 4974-4979. [CrossRef]

187. Kumar, M.; Singh, J.; Singh, M.K.; Singhal, A.; Thakur, I.S. Investigating the degradation process of kraft lignin by $\beta$-proteobacterium, Pandoraea sp. ISTKB. Environ. Sci. Pollut. Res. 2015, 22, 15690-15702. [CrossRef] [PubMed]

188. Peng, X.; Misawa, N.; Harayama, S. Isolation and characterization of thermophilic Bacilli degrading cinnamic, 4-coumaric, and ferulic acids. Appl. Environ. Microbiol. 2003, 69, 1417-1427. [CrossRef] [PubMed]

189. Duan, J.; Huo, H.; Du, W.J.; Liang, J.D.; Wang, D.Q.; Yang, S.C. Biodegradation of kraft lignin by a newly isolated anaerobic bacterial strain, Acetoanaerobium sp. WJDL-Y2. Lett. Appl. Microbiol. 2015, 62, 55-62. [CrossRef] [PubMed]

190. Zheng, Z.; Shetty, K. Solid-state bioconversion of phenolics from cranberry pomace and role of Lentinus edodes beta-glucosidase. J. Agric. Food Chem. 2000, 48, 895-900. [CrossRef] [PubMed]

191. Brosnan, B.; Coffey, A.; Arendt, E.K.; Furey, A. Rapid identification, by use of the LTQ Orbitrap hybrid FT mass spectrometer, of antifungal compounds produced by lactic acid bacteria. Anal. Bioanal. Chem. 2012, 403, 2983-2995. [CrossRef]

192. Broberg, A.; Jacobsson, K.; Ström, K.; Schnürer, J. Metabolite profiles of lactic acid bacteria in grass silage. Appl. Environ. Microbiol. 2007, 73, 5547-5552. [CrossRef]

193. Tian, R.-R.; Qiu-Hong Pan, Q.-H.; Zhan, J.-C.; Li, J.-M.; Wan, S.-B.; Zhang, Q.-H.; Huang, W.-D. Comparison of phenolic acids and flavan-3-ols during wine fermentation of grapes with different harvest times. Molecules 2009, 14, 827-838. [CrossRef]

194. Klepacka, J.; Fornal, L. Ferulic acid and its position among the phenolic compounds of wheat. Crit. Rev. Food Sci. Nutr. 2006, 46, 639-647. [CrossRef]

195. Antognoni, F.; Mandrioli, R.; Potente, G.; Taneyo Saa, D.L.; Gianotti, A. Changes in carotenoids, phenolic acids and antioxidant capacity in bread wheat doughs fermented with different lactic acid bacteria strains. Food Chem. 2019, 292, 211-216. [CrossRef]

196. Dey, T.B.; Kuhad, R.C. Enhanced production and extraction of phenolic compounds from wheat by solid-state fermentation with Rhizopus oryzae RCK2012. Biotechnol. Rep. 2014, 4, 120-127.

197. Rodriguez, A.; Chen, Y.; Khoomrung, S.; Özdemir, E.; Borodina, I.; Nielsen, J. Comparison of the metabolic response to over-production of $p$-coumaric acid in two yeast strains. Metab. Eng. 2017, 44, 265-272. [CrossRef] [PubMed]

198. Vargas-Tah, A.; Martínez, L.M.; Hernández-Chávez, G.; Rocha, M.; Martínez, A.; Bolívar, F.; Gosset, G. Production of cinnamic and $p$-hydroxycinnamic acid from sugar mixtures with engineered Escherichia coli. Microb. Cell Factories 2015, 14, 6. [CrossRef] [PubMed]

199. Kitade, Y.; Hashimoto, R.; Suda, M.; Hiraga, K.; Inui, M. Production of 4-hydroxybenzoic acid by an aerobic growth-arrested bioprocess using metabolically engineered Corynebacterium glutamicum. Appl. Environ. Biotechnol. 2018, 84, e02587-17.

200. Porro, D.; Branduardi, P. Yeast cell factory: Fishing for the best one or engineering it? Microb. Cell Factories 2009, 8, 51. [CrossRef]

201. Gottardi, M.; Reifenrath, M.; Boles, E.; Tripp, J. Pathway engineering for the production of heterologous aromatic chemicals and their derivatives in Saccharomyces cerevisiae: Bioconversion from glucose. Fems Yeast Res. 2017, 17, fox035. [CrossRef]

202. Lee, J.-H.; Wendisch, V.F. Biotechnological production of aromatic compounds of the extended shikimate pathway from renewable biomass. J. Biotechnol. 2017, 257, 211-221. [CrossRef]

203. Meijnen, J.; Verhoef, S.; Briedjlal, A.A.; de Winde, J.H.; Ruijssenaars, H.J. Improved p-hydroxybenzoate production by engineered Pseudomonas putida S12 by using a mixed-substrate feeding strategy. Appl. Microbiol. Biotechnol. 2011, 90, 885-893. [CrossRef]

204. Rodrigues, J.L.; Coutoa, M.R.; Araújo, R.G.; Prather, K.L.J.; Kluskens, L.; Rodrigues, L.R. Hydroxycinnamic acids and curcumin production in engineered Escherichia coli using heat shock promoters. Biochem. Eng. J. 2017, 125, 41-49. [CrossRef]

205. Civolani, C.; Barghini, P.; Roncetti, A.R.; Ruzzi, M.; Schiesser, A. Bioconversion of ferulic acid into vanillic acid by means of a vanillate-negative mutant of Pseudomonas fluorescens strain BF13. Appl. Environ. Microbiol. 2000, 66, 2311-2317. [CrossRef] 
206. Yi, J.; Li, K.; Draths, K.M.; Frost, J.W. Modulation of phosphoenolpyruvate synthase expression increases shikimate pathway product yields in E. coli. Biotechnol. Prog. 2002, 1141-1148. [CrossRef] [PubMed]

207. Li, Y.; Li, J.; Qian, B.; Cheng, L.; Xu, S.; Wang, R. De Novo biosynthesis of $p$-coumaric acid in E. coli with a trans-cinnamic acid 4-hydroxylase from the Amaryllidaceae plant Lycoris aurea. Molecules 2018, 23, 3185. [CrossRef] [PubMed]

208. Liu, Q.; Yu, T.; Li, X.; Chen, Y.; Campbell, K.; Nielsen, J.; Chen, Y. Rewiring carbon metabolism in yeast for high level production of aromatic chemicals. Nat. Commun. 2019, 10, 4976. [CrossRef] [PubMed]

209. An, D.G.; Cha, M.N.; Nadarajan, S.P.; Kim, B.G.; Ahn, J.-H. Bacterial synthesis of four hydroxycinnamic acids. Appl. Biol. Chem. 2016, 59, 173-179. [CrossRef]

210. Furuya, T.; Arai, Y.; Kino, K. Biotechnological production of caffeic acid by bacterial cytochrome P450 CYP199A2. Appl. Environ. Microbiol. 2012, 78, 6087-6094. [CrossRef] [PubMed]

211. Lin, Y.; Yan, Y. Biosynthesis of caffeic acid in Escherichia coli using its endogenous hydroxylase complex. Microb. Cell Factories 2012, 11, 42-51. [CrossRef]

212. Berner, M.; Krug, D.; Bihlmaier, C.; Vente, A.; Müller, R.; Bechthold, A. Genes and enzymes involved in caffeic acid biosynthesis in the Actinomycete Saccharothrix espanaensis. J. Bacteriol. 2006, 188, 2666-2673. [CrossRef]

213. Rodrigues, J.L.; Araújo, R.G.; Prather, K.L.J.; Kluskens, L.D.; Rodrigues, L.R. Heterologous production of caffeic acid from tyrosine in Escherichia coli. Enzym. Microb. Technol. 2015, 71, 36-44. [CrossRef]

214. Liu, L.; Liu, H.; Zhang, W.; Yao, M.; Li, B.; Liu, D.; Yuan, Y. Engineering the biosynthesis of caffeic acid in Saccharomyces cerevisiae with heterologous enzyme combinations. Engineering 2019, 5, 287-295. [CrossRef]

215. Kim, Y.H.; Kwon, T.; Yang, H.J.; Kim, W.; Youn, H.; Lee, J.Y.; Youn, B. Gene engineering, purification, crystallization and preliminary $\mathrm{X}$-ray diffraction of cytochrome $\mathrm{P} 450 \mathrm{p}$-coumarate-3-hydroxylase $\left(\mathrm{C}_{3} \mathrm{H}\right)$, the Arabidopsis membrane protein. Protein Expr. Purif. 2011, 79, 149-155. [CrossRef]

216. Kang, S.-Y.; Choi, O.; Lee, J.K.; Hwang, B.Y.; Uhm, T.-B.; Hong, Y.-S. Artificial biosynthesis of phenylpropanoic acids in a tyrosine overproducing Escherichia coli strain. Microb. Cell Factories 2012, 11, 153. [CrossRef] [PubMed]

217. Nair, R.B.; Bastress, K.L.; Ruegger, M.O.; Denault, J.W.; Chapple, C. The Arabidopsis thaliana REDUCED EPIDERMAL FLUORESCENCE1 gene encodes an aldehyde dehydrogenase involved in ferulic acid and sinapic acid biosynthesis. Plant Cell 2004, 16, 544-554. [CrossRef] [PubMed]

218. Kallscheuer, N.; Marienhagen, J. Corynebacterium glutamicum as platform for the production of hydroxybenzoic acids. Microb. Cell Factories 2018, 17, 70. [CrossRef] [PubMed]

219. Muir, R.M.; Ibáñez, A.M.; Uratsu, S.L.; Ingham, E.S.; Leslie, C.A.; McGranahan, G.H.; Batra, N.; Goyal, S.; Joseph, J.; Jemmis, E.D.; et al. Mechanism of gallic acid biosynthesis in bacteria (Escherichia coli) and walnut (Juglans regia). Plant Mol. Biol. 2011, 75, 555-565. [CrossRef] [PubMed]

220. Kambourakis, S.; Draths, K.M.; Frost, J.W. Synthesis of gallic acid and pyrogallol from glucose: replacing natural product isolation with microbial catalysis. J. Am. Chem. Soc. 2000, 122, 9042-9043. [CrossRef]

221. Sun, X.; Lin, Y.; Yuan, Q.; Yan, Y. Biological production of muconic acid via a prokaryotic 2,3-dihydroxybenzoic acid decarboxylase. ChemSusChem 2014, 7, 2478-2481. [CrossRef]

222. Okai, N.; Masuda, T.; Takeshima, Y.; Tanaka, K.; Yoshida, K.; Miyamoto, M.; Ogino, C.; Kondo, A. Biotransformation of ferulic acid to protocatechuic acid by Corynebacterium glutamicum ATCC 21420 engineered to express vanillate $o$-demethylase. Amb Express 2017, 7, 130. [CrossRef]

223. Segura, A.; Bünz, P.V.; D'Argenio, D.A.; Ornston, L.N. Genetic analysis of a chromosomal region containing van $A$ and $v a n B$, genes required for conversion of either ferulate or vanillate to protocatechuate in Acinetobacter. J. Biotechnol. 1999, 181, 3494-3504.

224. Upadhyay, P.; Singh, N.K.; Tupe, R.; Odenath, A.; Lali, A. Biotransformation of corn bran derived ferulic acid to vanillic acid using engineered Pseudomonas putida KT2440. Prep. Biochem. Biotechnol. 2019, 50, 341-348. [CrossRef]

225. Kamimura, N.; Goto, T.; Takahashi, K.; Kasai, D.; Otsuka, Y.; Nakamura, M.; Katayama, Y.; Fukuda, M.; Masai, E. A bacterial aromatic aldehyde dehydrogenase critical for the efficient catabolism of syringaldehyde. Sci. Rep. 2017, 7, 44422. [CrossRef]

226. Seshime, Y.; Juvvadi, P.R.; Kitamoto, K.; Ebizuka, Y.; Nonaka, T.; Fujii, I. Aspergillus oryzae type III polyketide synthase CsyA is involved in the biosynthesis of 3,5-dihydroxybenzoic acid. Bioorg. Med. Chem. Lett. 2010, 20, 4785-4788. [CrossRef] [PubMed] 
227. Gao, L.; Cai, M.; Shen, W.; Zhou, X.; Zhang, Y. Engineered fungal polyketide biosynthesis in Pichia pastoris: A potential excellent host for polyketide production. Microb. Cell Factories 2013, 12, 77. [CrossRef] [PubMed]

228. Xu, Q.; Bai, C.; Liu, Y.; Song, L.; Tian, L.; Yan, Y.; Zhou, J.; Zhou, X.; Zhang, Y.; Cai, M. Modulation of acetate utilization in Komagataella phaffii by metabolic engineering of tolerance and metabolism. Biotechnol. Biofuels 2019, 12, 61. [CrossRef] [PubMed]

229. Kong, C.; Huang, H.; Xue, Y.; Liu, Y.; Peng, Q.; Liu, Q.; Xu, Q.; Zhu, Q.; Yin, Y.; Zhou, X.; et al. Heterologous pathway assembly reveals molecular steps of fungal terreic acid biosynthesis. Sci. Rep. 2018, 8, 2116. [CrossRef] [PubMed]

230. Hitschler, J.; Boles, E. De novo production of aromatic $m$-cresol in Saccharomyces cerevisiae mediated by heterologous polyketide synthases combined with a 6-methylsalicylic acid decarboxylase. Metab. Eng. Commun. 2019, 9, e00093. [CrossRef]

231. Yang, D.; Kim, W.J.; Yoo, S.M.; Choi, J.H.; Ha, S.H.; Leea, M.H.; Lee, S.Y. Repurposing type III polyketide synthase as a malonyl-CoA biosensor for metabolic engineering in bacteria. Proc. Natl. Acad. Sci. USA 2018, 115, 9835-9844. [CrossRef]

232. Braesel, J.; Fricke, J.; Schwenk, D.; Hoffmeister, D. Biochemical and genetic basis of orsellinic acid biosynthesis and prenylation in a stereaceous basidiomycete. Fungal Genet. Biol. 2017, 98, 12-19. [CrossRef]

233. Tan, Z.; Clomburg, J.M.; Gonzalez, R. Synthetic pathway for the production of olivetolic acid in Escherichia coli. ACS Synth. Biol. 2018, 7, 1886-1896. [CrossRef]

234. Averesch, N.J.H.; Prima, A.; Krömer, J.O. Enhanced production of para-hydroxybenzoic acid by genetically engineered Saccharomyces cerevisiae. Bioprocess Biosyst. Eng. 2017, 2017, 1283-1289. [CrossRef]

235. Purwanto, H.S.; Kang, M.-S.; Ferrer, L.; Han, S.-S.; Lee, J.-Y.; Kim, H.-S.; Lee, J.-H. Rational engineering of the shikimate and related pathways in Corynebacterium glutamicum for 4-hydroxybenzoate production. J. Biotechnol. 2018, 282, 92-100. [CrossRef]

236. Lenzen, C.; Wynands, B.; Otto, M.; Bolzenius, J.; Mennicken, P.; Blank, L.M.; Wierckx, M. High-Yield Production of 4-hydroxybenzoate from glucose or glycerol by an engineered Pseudomonas taiwanensis VLB120. Front. Bioeng. Biotechnol. 2019, 7, 130. [CrossRef] [PubMed]

237. Noda, S.; Shirai, T.; Oyama, S.; Kondo, A. Metabolic design of a platform Escherichia coli strain producing various chorismate derivatives. Metab. Eng. 2016, 33, 119-129. [CrossRef] [PubMed]

238. Weber, C.; Brückner, C.; Weinreb, S.; Lehr, C.; Essl, C.; Boles, E. Biosynthesis of cis,cis-muconic acid and its aromatic precursors, catechol and protocatechuic acid, from renewable feedstocks by Saccharomyces cerevisiae. Appl. Environ. Microbiol. 2012, 78, 8421-8430. [CrossRef] [PubMed]

239. Li, W.; Xie, D.; Frost, J.W. Benzene-free synthesis of catechol: interfacing microbial and chemical catalysis. J. Am. Chem. Soc. 2005, 127, 2874-2882. [CrossRef]

240. Chen, Z.; Shen, X.; Wang, J.; Wang, J.; Yuan, Q.; Yan, Y. Rational engineering of $p$-hydroxybenzoate hydroxylase to enable efficient gallic acid synthesis via a novel artificial biosynthetic pathway. Biotechnol. Bioeng. 2017, 114, 2571-2580. [CrossRef]

241. Noda, S.; Shirai, T.; Mori, Y.; Oyama, S.; Kondo, A. Engineering a synthetic pathway for maleate in Escherichia coli. Nat. Commun. 2017, 8, 1153. [CrossRef]

242. Chen, Z.; Sun, X.; Li, Y.; Yan, Y.; Yuan, Q. Metabolic engineering of Escherichia coli for microbial synthesis of monolignols. Metab. Eng. 2017, 39, 102-109. [CrossRef]

243. Rodriguez, A.; Kildegaard, K.R.; Li, M.; Borodina, I.; Nielsen, J. Establishment of a yeast platform strain for production of $p$-coumaric acid through metabolic engineering of aromatic amino acid biosynthesis. Metab. Eng. 2015, 31, 181-188. [CrossRef]

244. Huang, Q.; Lin, Y.; Yan, Y. Caffeic acid production enhancement by engineering a phenylalanine over-producing Escherichia coli strain. Biotechnol. Bioeng. 2013, 110, 3188-3196. [CrossRef]

245. Gao, Y.; Ma, S.; Wang, M.; Feng, X.-Y. Characterization of free, conjugated, and bound phenolic acids in seven commonly consumed vegetables. Molecules 2017, 22, 1878. [CrossRef]

246. Xu, F.; Sun, R.-C.; Sun, J.-X.; Liu, C.-F.; He, B.-H.; Fan, J.-S. Determination of cell wall ferulic and $p$-coumaric acids in sugarcane bagasse. Anal. Chim. Acta 2005, 552, 207-217. [CrossRef]

247. Nardini, M.; Cirillo, E.; Natella, F.; Mencarelli, D.; Comisso, A.; Scaccini, C. Detection of bound phenolic acids: Prevention by ascorbic acid and ethylenediaminetetraacetic acid of degradation of phenolic acids during alkaline hydrolysis. Food Chem. 2002, 79, 119-124. [CrossRef] 
248. Bouzid, O.; Navarro, D.; Roche, M.; Asther, M.; Haon, M.; Delattre, M.; Lorquin, J.; Labat, M.; Asther, M.; Lesage-Meessen, L. Fungal enzymes as a powerful tool to release simple phenolic compounds from olive oil by-product. Process Biochem. 2005, 40, 1855-1862. [CrossRef]

249. Zhang, S.-B.; Zhai, H.-C.; Wang, L.; Yu, G.-H. Expression, purification and characterization of a feruloyl esterase A from Aspergillus flavus. Protein Expr. Purif. 2013, 92, 36-40. [CrossRef] [PubMed]

250. Gopalan, N.; Nampoothiri, K.M. Biorefining of wheat bran for the purification of ferulic acid. Biocatal. Agric. Biotechnol. 2018, 15, 304-310. [CrossRef]

251. Xu, Z.; Wang, T.; Zhang, S. Extracellular secretion of feruloyl esterase derived from Lactobacillus crispatus in Escherichia coli and its application for ferulic acid production. Bioresour. Technol. 2019, 288, 121526. [CrossRef]

252. Torres-Mancera, M.T.; Cordova-López, J.; Rodríguez-Serrano, G.; Roussos, S.; Ramírez-Coronel, M.A.; Favela-Torres, E.; Saucedo-Castañeda, G. Enzymatic extraction of hydroxycinnamic acids from coffee pulp. Food Technol. Biotechnol. 2011, 49, 369-373.

253. Curiel, J.; Betancor, L.; de las Rivas, B.; Muñoz, R.; Guisan, J.M.; Fernández-Lorente, G. Hydrolysis of tannic acid catalyzed by immobilized-stabilized derivatives of tannase from Lactobacillus plantarum. J. Agric. Food Chem. 2010, 58, 6403-6409. [CrossRef]

254. Wu, H.; Li, H.; Xue, Y.; Luo, G.; Gan, L.; Liu, J.; Mao, L.; Long, M. High efficiency co-production of ferulic acid and xylooligosaccharides from wheat bran by recombinant xylanase and feruloyl esterase. Biochem. Eng. J. 2017, 120, 41-48. [CrossRef]

255. Yu, P.; Maenz, D.D.; Mckinnon, J.J.; Racz, V.J.; Christensen, D.A. Release of ferulic acid from oat hulls by Aspergillus ferulic acid esterase and Trichoderma xylanase. J. Agrocultural Food Chem. 2002, 50, 1625-1630. [CrossRef]

256. Chemat, F.; Fabiano-Tixier, A.S.; Vian, M.A.; Allaf, T.; Vorobiev, E. Solvent-free extraction of food and natural products. Trac Trends Anal. Chem. 2015, 71, 157-168. [CrossRef]

257. Carabias-Martínez, R.; Rodríguez-Gonzalo, E.; Revilla-Ruiz, P.; Hernández-Méndez, J. Pressurized liquid extraction in the analysis of food and biological samples. J. Chromatogr. 2005, 1089, 1-17. [CrossRef] [PubMed]

258. Chemat, F.; Rombaut, N.; Sicaire, A.-G.; Meullemiestre, A.; Fabiano-Tixier, A.-S.; Abert-Vian, M. Ultrasound assisted extraction of food and natural products. Mechanisms, techniques, combinations, protocols and applications. A review. Ultrason. Sonochem. 2017, 34, 540-560. [CrossRef] [PubMed]

259. Wu, T.; Yan, J.; Liu, R.; Marcone, M.F.; Aisa, H.A.; Tsao, R. Optimization of microwave-assisted extraction of phenolics from potato and its downstream waste using orthogonal array design. Food Chem. 2012, 133, 1292-1298. [CrossRef]

260. Virot, M.; Tomao, V.; Le Bourvellec, C.; Renard, C.M.C.G.; Chemat, F. Towards the industrial production of antioxidants from food processing by-products with ultrasound-assisted extraction. Ultrason. Sonochem. 2010, 17, 1066-1074. [CrossRef]

261. Ma, Y.-Q.; Chen, J.-C.; Liu, D.-H.; Ye, X.-Q. Simultaneous extraction of phenolic compounds of citrus peel extracts: Effect of ultrasound. Ultrason. Sonochem. 2009, 16, 57-62. [CrossRef]

262. Verberne, M.C.; Brouwer, N.; Delbianco, F.; Linthorst, H.J.; Bol, J.F.; Verpoorte, R. Method for the extraction of the volatile compound salicylic acid from tobacco leaf material. Phytochem. Anal. 2002, 13, 45-50. [CrossRef]

263. Liazid, A.; Palma, M.; Brigui, J.; Barroso, C.G. Investigation on phenolic compounds stability during microwave-assisted extraction. J. Chromatogr. A 2007, 1140, 29-34. [CrossRef]

264. Qiao, L.; Ye, X.; Sun, Y.; Ying, J.; Shen, Y.; Chen, J. Sonochemical effects on free phenolic acids under ultrasound treatment in a model system. Ultrason. Sonochem. 2013, 20, 1017-1025. [CrossRef]

265. Christian, K.R.; Jackson, J. Changes in total phenolic and monomeric anthocyanin composition and antioxidant activity of three varieties of sorrel (Hibiscus sabdariffa) during maturity. J. Food Compos. Anal. 2009, 22, 663-667. [CrossRef]

266. Waksmundzka - Hajnos, M.; Oniszczuk, A.; Szewczyk, K.; Wianowska, D. Effect of sample-preparation methods on the HPLC quantitation of some phenolic acids in plant materials. Acta Chromatogr. 2007, 19, 227-237.

267. Yan-Ying, Y.; Wei, Z.; Shu-Wen, C. Extraction of ferulic acid and caffeic acid with ionic liquids. Chin. J. Anal. Chem. 2007, 35, 1726-1730. [CrossRef] 
268. Wang, X.H.; Wang, G.Y.; Hou, Y.Y.; Qin, L. Extraction of ferulic acid and vanilla acid by hydrophobic ionic liquid 1-hexyl-3-methylimidazolium hexafluorophosphate. J. Food Sci. Technol. 2018, 55, 3508-3517. [CrossRef] [PubMed]

269. Žiaková, A.; Brandšteterová, E.; Blahová, B. Matrix solid-phase dispersion for the liquid chromatographic determination of phenolic acids in Melissa officinalis. J. Chromatogr. A 2003, 983, 271-275. [CrossRef]

270. Rahman, M. Application of computational methods in isolation of plant secondary metabolites. In Computational Phytochemistry; Sarker, S.D., Nahar, L., Eds.; Elsevier BV: London, UK, 2018; pp. 107-139.

271. Zhang, L.; Zhang, W.; Chen, W.; Chen, G. Simultaneous determination of five bioactive constituents in Rhizoma Chuanxiong by capillary electrophoresis with a carbon nanotube-polydimethylsiloxane composite electrode. J. Pharm. Biomed. Anal. 2016, 131, 107-112. [CrossRef]

272. Emwas, A.H.; Roy, R.; McKay, R.T.; Tenori, L.; Saccenti, E.; Gowda, G.A.N.; Raftery, D.; Alahmari, F.; Jaremko, L.; Jaremko, M.; et al. NMR spectroscopy for metabolomics research. Metabolites 2019, 9, 123. [CrossRef]

273. Monošík, R.; Stred'anský, M.; Šturdík, E. Biosensors - classification, characterization. Acta Chim. Slovaca 2012, 5, 109-120.

274. Diaconu, M.; Litescu, S.C.; Radu, G.L. Laccase-MWCNT-chitosan biosensor-A new tool for total polyphenolic content evaluation from in vitro cultivated plants. Sens. Actuators B Chem. 2010, 145, 800-806. [CrossRef]

275. ElKaoutit, M.; Naranjo-Rodriguez, I.; Temsamani, K.; de la Vega, M.D.; de Cisneros, J.L. Dual laccase-tyrosinase based sonogel-carbon biosensor for monitoring polyphenols in beers. J. Agric. Food Chem. 2007, 55, 8011-8018. [CrossRef]

276. Jarosz-Wilkołazka, A.; Ruzgas, T.; Gorton, L. Use of laccase-modified electrode for amperometric detection of plant flavonoids. Enzym. Microb. Technol. 2004, 35, 238-241. [CrossRef]

277. Carralero Sanz, V.; Luz Mena, M.; González-Cortés, A.; Yáñez-Sedeño, P.; Pingarrón, J.M. Development of a tyrosinase biosensor based on gold nanoparticles-modified glassy carbon electrodes: Application to the measurement of a bioelectrochemical polyphenols index in wines. Anal. Chim. Acta 2005, 528, 1-8. [CrossRef]

278. Mello, L.D.; Sotomayor, M.D.P.T.; Kubota, L.T. HRP-based amperometric biosensor for the polyphenols determination in vegetables extract. Sens. Actuators B Chem. 2003, 96, 636-645. [CrossRef]

279. Ambri, F.; D'Ambrosio, V.; Blasi, R.D.; Maury, J.; Jacobsen, S.A.B.; McCloskey, D.; Jensen, M.K.; Keasling, J.D. High-resolution scanning of optimal biosensor reporter promoters in yeast. Acs Synth. Biol. 2020, 9, 218-226. [CrossRef] [PubMed]

280. Rogers, J.K.; Taylor, N.D.; Church, G.M. Biosensor-based engineering of biosynthetic pathways. Curr. Opin. Biotechnol. 2016, 42, 84-91. [CrossRef] [PubMed]

281. Alvarez-Gonzalez, G.; Dixon, N. Genetically encoded biosensors for lignocellulose valorization. Biotechnol. Biofuels 2019, 12, 246. [CrossRef] [PubMed]

282. Siedler, S.; Khatri, N.K.; Zsohar, A.; Kjærbølling, I.; Vogt, M.; Hammar, P.; Nielsen, C.F.; Marienhagen, J.; Sommer, M.O.A.; Joensson, H.N. Development of a bacterial biosensor for rapid screening of yeast $p$-coumaric acid production. Acs Synth. Biol. 2017, 6, 1860-1869. [CrossRef]

283. Frei, C.S.; Qian, S.; Cirino, P.C. New engineered phenolic biosensors based on the AraC regulatory protein. Protein Eng. Des. Sel. 2018, 31, 213-220. [CrossRef]

284. Qian, S.; Li, Y.; Cirino, P.C. Biosensor-guided improvements in salicylate production by recombinant Escherichia coli. Microb. Cell Factories 2019, 18, 18. [CrossRef]

285. Meyer, A.J.; Segall-Shapiro, T.H.; Glassey, E.; Zhang, J.; Voigt, C.A. Escherichia coli “Marionette” strains with 12 highly optimized small-molecule sensors. Nat. Chem. Biol. 2019, 15, 196-204. [CrossRef]

286. Machado, L.F.M.; Dixon, N. Development and substrate specificity screening of an in vivo biosensor for the detection of biomass derived aromatic chemical building blocks. Chem. Commun. 2016, 52, 11402-11405. [CrossRef]

287. Jha, R.K.; Kern, T.L.; Fox, D.T.; Strauss, C.E.M. Engineering an Acinetobacter regulon for biosensing and high-throughput enzyme screening in E. coli via flow cytometry. Nucleic Acids Res. 2014, 42, 8150-8160. [CrossRef] [PubMed]

288. Machado, L.F.M.; Currin, A.; Dixon, N. Directed evolution of the PcaV allosteric transcription factor to generate a biosensor for aromatic aldehydes. J. Biol. Eng. 2019, 13, 91. [CrossRef] [PubMed] 
289. Jha, R.K.; Bingen, J.M.; Johnson, C.W.; Kern, T.L.; Khanna, P.; Trettel, D.S.; Strauss, C.E.M.; Beckham, G.T.; Dale, T. A protocatechuate biosensor for Pseudomonas putida KT2440 via promoter and protein evolution. Metab. Eng. Commun. 2018, 6, 33-38. [CrossRef] [PubMed]

290. Jha, R.K.; Chakraborti, S.; Kern, T.L.; Fox, D.T.; Strauss, C.E.M. Rosetta comparative modeling for library design: Engineering alternative inducer specificity in a transcription factor. Proteins 2015, 83, 1327-1340. [CrossRef] [PubMed]

291. Strachan, C.R.; Singha, R.; VanInsberghe, D.; Ievdokymenko, K.; Budwill, K.; Mohn, W.W.; Eltis, L.D.; Hallam, S.J. Metagenomic scaffolds enable combinatorial lignin transformation. Proc. Natl. Acad. Sci. USA 2014, 111, 10143-10148. [CrossRef]

292. Varman, A.M.; Follenfant, R.; Liu, F.; Davis, R.W.; Lin, Y.K.; Singh, S. Hybrid phenolic-inducible promoters towards construction of self-inducible systems for microbial lignin valorization. Biotechnol. Biofuels 2018, 11, 182. [CrossRef]

293. Kunjapur, A.M.; Prather, K.L.J. Development of a vanillate biosensor for the vanillin biosynthesis pathway in E. coli. Acs Synth. Biol. 2019, 8, 1958-1967. [CrossRef]

294. Jha, R.K.; Narayanan, N.; Pandey, N.; Bingen, J.M.; Kern, T.L.; Johnson, C.W.; Strauss, C.E.M.; Beckham, G.T.; Hennelly, S.P.; Dale, T. Sensor-enabled alleviation of product inhibition in chorismate pyruvate-lyase. Acs Synth. Biol. 2019, 8, 775-786. [CrossRef]

295. Chen, J.X.; Steel, H.; Wu, Y.-H.; Wang, Y.; Xu, J.; Rampley, C.P.N.; Thompson, I.P.; Papachristodoulou, A.; Huang, W.E. Development of aspirin-inducible biosensors in Escherichia coli and SimCells. Appl. Environ. Microbiol. 2019, 85, e02959-18. [CrossRef]

296. Xue, H.; Shi, H.; Yu, Z.; He, S.; Liu, S.; Hou, Y.; Pan, X.; Wang, H.; Zheng, P.; Cui, C.; et al. Design, construction, and characterization of a set of biosensors for aromatic compounds. Acs Synth. Biol. 2014, 3, 1011-1014. [CrossRef]

297. Kawaguchi, H.; Katsuyama, Y.; Danyao, D.; Kahar, P.; Nakamura-Tsuruta, S.; Teramura, H.; Wakai, K.; Yoshihara, K.; Hiromichi, M.; Ogino, C.; et al. Caffeic acid production by simultaneous saccharification and fermentation of kraft pulp using recombinant Escherichia coli. Appl. Microbiol. Biotechnol. 2017, 101, 5279-5290. [CrossRef] [PubMed]

298. Verhoef, S.; Ballerstedt, H.; Volkers, R.J.; de Winde, J.H.; Ruijssenaars, H.J. Comparative transcriptomics and proteomics of $p$-hydroxybenzoate producing Pseudomonas putida S12: Novel responses and implications for strain improvement. Appl. Microbiol. Biotechnol. 2010, 87, 679-690. [CrossRef] [PubMed]

299. Wagner, S.; Klepsch, M.M.; Schlegel, S.; Appel, A.; Draheim, R.; Tarry, M.; Högbom, M.; van Wijk, K.J.; Slotboom, D.J.; Persson, J.O.; et al. Tuning Escherichia coli for membrane protein overexpression. Proc. Natl. Acad. Sci. USA 2008, 105, 14371-14376. [CrossRef] [PubMed]

300. Yu, S.; Plan, M.R.; Winter, G.; Kromer, J.O. Metabolic engineering of Pseudomonas putida KT2440 for the production of para-hydroxy benzoic acid. Front. Bioeng. Biotechnol. 2016, 4, 90. [CrossRef] [PubMed]

301. Liu, L.; Li, W.; Li, X.; Sun, X.; Yuan, Q. Constructing an efficient salicylate biosynthesis platform by Escherichia coli chromosome integration. J. Biotechnol. 2019, 298, 5-10. [CrossRef]

302. Verhoef, S.; Gao, G.; Ruijssenaars, H.J.; de Winde, J.H. Crude glycerol as feedstock for the sustainable production of $p$-hydroxybenzoate by Pseudomonas putida S12. New Biotechnol. 2014, 31, 114-119. [CrossRef]

303. Lütke-Eversloh, T.; Stephanopoulos, G. L-Tyrosine production by deregulated strains of Escherichia coli. Appl. Microbiol. Biotechnol. 2007, 75, 103-110. [CrossRef]

304. Wang, Z.; Liu, J.; Chen, L.; Zeng, A.-P.; Solem, C.; Jensen, P.R. Alterations in the transcription factors GntR1 and RamA enhance the growth and central metabolism of Corynebacterium glutamicum. Metab. Eng. 2018, 48, 1-12. [CrossRef]

305. Tinikul, R.; Chenprakhon, P.; Maenpuen, S.; Chaiyen, P. Biotransformation of plant-derived phenolic acids. Biotechnol. J. 2018, 13, e1700632. [CrossRef]

(C) 2020 by the authors. Licensee MDPI, Basel, Switzerland. This article is an open access article distributed under the terms and conditions of the Creative Commons Attribution (CC BY) license (http://creativecommons.org/licenses/by/4.0/). 